\title{
A Scenario-Based Management of Water Resources and Supply Systems Using a Combined System Dynamics and Compromise Programming Approach
}

Marzieh Momeni

University of Tehran

Kourosh Behzadian ( $\nabla$ kourosh.behzadian@uwl.ac.uk)

University of West London https://orcid.org/0000-0002-1459-8408

Hossein Yousefi

University of Tehran

Sina Zahedi

University of Tehran

\section{Research Article}

Keywords: compromise programming, groundwater resources, water conservation, sustainable groundwater extraction, system dynamics, water supply systems

Posted Date: June 4th, 2021

DOl: https://doi.org/10.21203/rs.3.rs-574796/v1

License: (c) (i) This work is licensed under a Creative Commons Attribution 4.0 International License.

Read Full License 
1 A Scenario-based Management of Water Resources and Supply Systems using a Combined

System Dynamics and Compromise Programming Approach

4 Abstract

5 Long-term sustainability in water supply systems is a major challenge due to water resources

6 depletion, climate change and population growth. This paper presents a scenario-based approach

7 for performance assessment of intervention strategies in water resources and supply systems

8 (WRSS). A system dynamics (SD) approach is used for modelling the key WRSS components and

9 their complex interactions with natural and human systems and is combined with a multi-criteria

10 decision analysis for sustainability performance assessment of strategies in each scenario. The

11 scenarios combine population growth rates with groundwater extraction limits and three

12 intervention strategies. The methodology was demonstrated on a real-world case study in Iran.

13 Results show scenario-based analysis can provide suitable strategies leading to long-term

14 sustainability of water resources for each scenario imposed on the water systems. For scenarios

15 with either no threshold or one threshold of groundwater extraction limit, the only effective

16 strategies for sustainable groundwater preservation are those involving agricultural water demand

17 decrease with an average recovery rate of $130 \%$ for groundwater resources while other strategies

\footnotetext{
${ }^{1}$ Department of Renewable Energies and Environment, Faculty of New Sciences and Technologies, University of Tehran, Tehran, Iran. Email: momeni.marzieh@gmail.com.

${ }^{2}$ Groundwater Research Institute, University of Tehran, Tehran, Iran.

3 School of Computing and Engineering, University of West London, London W5 5RF, UK. Email: kourosh.behzadian@uwl.ac.uk.*Corresponding Author

${ }^{4}$ Department of Renewable Energies and Environment, Faculty of New Sciences and Technologies, University of Tehran, Tehran, Iran. Email: hosseinyousefi@ut.ac.ir.

${ }^{5}$ Groundwater Research Institute, University of Tehran, Tehran, Iran. Email: zahedi.sina@alumni.ut.ac.ir.
} 
18 of agricultural groundwater abstraction (constant/increase rates) fail to sustainably recover

19 groundwater resources. However, all analysed strategies can provide sustainability of water

20 resources with an average recovery rate of $33 \%$ for groundwater resources only when scenarios

21 with two threshold limits are in place. The impact of scenarios on groundwater conservation is

22 quite minor for population growth rates with an average recovery rate of $11 \%$ compared to

23 groundwater extraction limits with an average recovery rate of $79 \%$ between no threshold and two

24 threshold limits.

25 Keywords: compromise programming; groundwater resources; water conservation; sustainable 26 groundwater extraction; system dynamics; water supply systems.

\section{Introduction}

28 While some regions in the world benefit from abundant freshwater supply, recent droughts showed

29 an urgent need for changing public perception of water and its efficiency globally (Ziolkowska \&

30 Ziolkowski 2016). The severe scarcity of water resources is currently a global concern that will

31 exacerbate in the future. While rapid population growth and economic development have also led

32 to higher water demand, climate change has increased the uncertainties of water resources (Xi \&

33 Poh 2013). Consequently, freshwater resources are depleted faster than the renewed ones due to

34 the high rates of consumption and changing water cycles. Water resources and supply systems

35 (WRSS) have always been faced with many drivers such as population growth, demand increase,

36 change in consumption patterns, urbanisation, climate change and infrastructure ageing that put a

37 high pressure on urban water services (Arfanuzzaman \& Atiq-Rahman 2017).

38 Countries in arid and semi-arid areas are more dependent on groundwater resources than other 39 water resources (Zahedi, 2017; Yousefi et al. 2019). However, this water resource has mainly been 
40 affected by climate change with altered precipitation regimes (Yousefi et al. 2018). Management

41 of agricultural water demands as the main consumer of water resources can specifically be used

42 for developing new water policies to reduce the tensions of water resources that also have a major

43 impact on domestic water supply (Michelsen \& Young 1993). In addition, sustainability of

44 groundwater resources is highly dependent on complex feedback loops between human and natural

45 systems in line with policy developments (Jia et al. 2019; Lizjen et al. 2014). This requires

46 continuous assessment of sustainable groundwater management by deep knowledge of present and

47 projected status of groundwater quantity and quality (Hosseini et al. 2019). Furthermore,

48 employing new management strategies can have a key role for reducing the impact of global

49 challenges on the performance of water supply systems. However, the complexity of interactions

50 between economic, social, and environmental issues features an intertwined challenge within the

51 context of groundwater resources management that needs rigorous analysis of potential solutions

52 with respect to various scenarios and assessment criteria to identify the best priorities for each

53 scenario. A major step for this is a proper modelling approach for performance simulation of real-

54 world systems. System Dynamics (SD) has shown to be an effective approach for integrated

55 modelling of long-term planning of socio-economic performance in complex systems (Sušnik et

56 al. 2012). The SD is also suitable for long-term performance assessment of the WRSS in which

57 feedbacks and complex interactions can be observed among variables and stock changes. The SD

58 can also be used for strategic planning of complex systems of water supply from water resources

59 (Hassanzadeh et al. 2012). For instance, Fang et al. (2019) developed a SD-based model to analyse

60 water allocation based on rapid urbanisation, excessive exploitation of resources and

61 environmental pollution. Phan et al. (2018) presented a feedback-driven SD model for simulation

62 of the supply and demand sides of a coastal freshwater system to assess and quantify potential 
63 climatic and socio-economic influences on the system vulnerability. Tianhong et al. (2019)

64 developed a SD-based model to investigate the complexity of social-economic-ecological

65 interactions throughout the urban water cycle.

66 Some research works have combined the SD modelling with other simulation models for decision

67 making in the water system context. For example, Baki et al. (2018) coupled the SD modelling

68 with the Urban Water Optioneering Tool (UWOT) to simulate urban water cycle and investigate

69 the diffusion of water conservation technologies into the domestic water sector. Few research

70 works have focused on the combination of the SD modelling with multi-criteria decision analysis

71 (MCDA) methods in the context of water resources management (Yang et al. 2019). For example,

72 Vo et al. (2002) coupled the SD modelling with Simple Additive Weighting method coupled to 73 analyse different lags in economic, social, and technical effects of large-scale urban water

74 management. Yang et al. (2019) assess the carrying capacity of water resources systems by 75 coupling the SD modelling with Analytic Hierarchy Process (AHP) to evaluate socio-economic

76 performance of the systems. The Compromise Programming (CP) method has also been used to

77 evaluate the performance of integrated urban water management and prioritise potential strategies

78 in urban water systems (Behzadian et al. 2014).

79 Despite the widespread use of the SD modelling in various applications of water systems, to the

80 best of the authors' knowledge, there is no previous work integrating the SD modelling with an

81 MCDA technique for a combined analysis of both plausible scenarios and strategies for water

82 resources and supply management. This paper makes use of integrating the $\mathrm{SD}$ with the $\mathrm{CP}$ tool to

83 develop an assessment framework for analysis of intervention strategies under future scenarios for

84 management of a complex system dynamics (SD) comprising groundwater and surface water

85 resources, water reuse and municipal water distribution networks. The water resources in this 
86 system can have interactions with neighbouring groundwater and trans-basin surface water

87 resources to support water supply of specific areas based on the sustainability indicators in water

88 systems. The SD model of the WRSS aims to evaluate the sustainability performance of depleting

89 groundwater for plausible scenarios and identify the most robust strategies over a long-term

90 planning horizon. Next section presents the methodology and then model development for business

91 as usual of the real-world WRSS. The results are then presented with critical analysis and

92 discussion along with summarising key findings and recommendations for future works.

\section{Methodology}

95 This paper presents a hybrid framework based on the combination of the SD and CP tools to 96 evaluate long-term sustainability performance of potential intervention strategies in WRSS under

97 plausible future scenarios. The modelling tools required for developing the methodology were the

98 VENSIM software for SD modelling (Niazi et al. 2014) and Excel platform for modelling the CP 99 method (Behzadian and Kapelan 2015). The planning horizon of the SD model was set for a long-

100 term (e.g. 3-50 years) as monthly timestep. Water demands were supplied from either groundwater 101 or surface water resources in the following order of priority: domestic, industrial and irrigation. 102 The methodology framework was developed based on the following steps:

103 - Step 1: Model development and calibration of water resources and supply systems by using 104 the SD modelling approach;

105 - Step 2: Performance assessment of the SD model for sustainability of water resources and 106 supply indicators for plausible scenarios, potential intervention strategies; 
- Step 3: prioritisation of the intervention strategies for each scenario with respect to key performance indicators (KPIs) derived from the sustainability performance based on the multi-criteria decision analysis by using the CP method.

110 Further details of the methodology and model development for the above steps are described 111 below.

\section{SD model development}

114 The SD model is used here mainly due to the dynamic and nonlinear behaviour of water

115 management systems that is subject to evolution and feedbacks in the decision-making

116 environment. This feature can be translated into various forms such as structural changes, time

117 delays, improvement (evolution), and interventions through policy-making. Causal loop diagrams

118 can be converted into stock and flow diagrams in the SD model to represent storage and

119 conveyance elements in the WRSS, respectively. More specifically, a stock is defined as a storage

120 element in the WRSS (e.g. water resources and service reservoirs) that accumulates or depletes

121 over time. A flow is defined as a conveyance element in the WRSS (e.g. trunk mains and

122 distribution mains) that shows the rate of change in a stock. The SD modelling adopts mass balance

123 equations of monthly inflows and outflows to stocks.

124 The SD was used here to develop the WRSS model in four main sub-systems (Figure 1) including

125 (1) surface water resources, (2) groundwater resources, (3) service reservoirs and water demands

126 (4) wastewater reuse. The SD defines the core of these sub-systems (e.g. resources and reservoirs)

127 as stocks connected to each other through flow and causal loop diagrams. More details of each 128 subsystem are outlined below. 


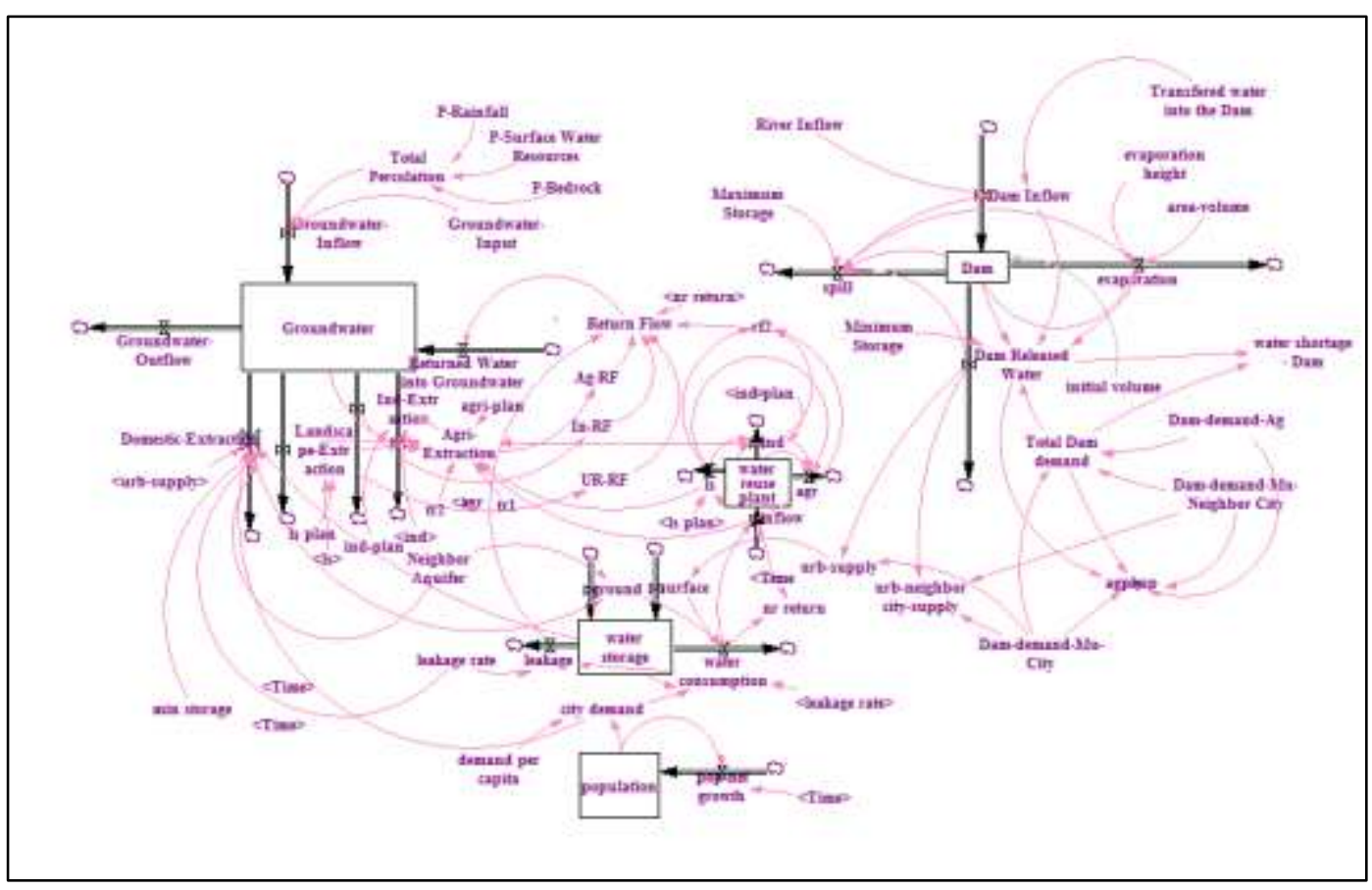

Figure 1: The SD model of the WRSS

132 The surface water subsystem (Figure 2a) supplies water for domestic and agricultural demands

133 and the main flows include (1) inflows from either directly its catchment or other upstream

134 catchments and (2) outflows for supplying demands. The groundwater subsystem (Figure 2b) is

135 developed based on the parameters of water budget in relevant aquifers. The parameters defined

136 here as flows are effective precipitation, percolation from surface water resources, recharging from

137 aquifer bedrock and inflow from or outflow to adjacent aquifers. Besides, groundwater extraction

138 has some flows that indicate the interactions of domestic, industrial, agricultural and landscape

139 demands. Part of the groundwater supplied for water demands can be assumed to return to relevant

140 aquifers. A regression-based model can be used for estimation of the groundwater water volume.

141 The service reservoir subsystem (Figure 2c) is fed by two inflows from groundwater and surface

142 water resources. It also has two outflows for distribution main leakage and domestic water 143 consumption. The service reservoir is connected to water demand stock and estimates future 
144 domestic water demand based on continues-time equations of population growth over a simulation

145 period. Water and wastewater reuse subsystem (Figure 2d) can be defined as a stock connecting

146 to water reuse plant and provides the process of returning the treated effluent for reuse in industrial,

147 landscape irrigation, and agricultural demands, respectively.

148 Due to the high priority of preserving groundwater resources from depletion due to excessive

149 extraction. it is assumed water demands are first supplied from surface water resources and any

150 remaining unmet demands are supplied from groundwater resources. (see also the schematic charts

151 of model development in S.1 of the supplementary materials).

\section{Scenarios and strategies}

153 Strategic planning and management of water systems require an analysis of potential intervention

154 strategies to mitigate the challenges related to environment (e.g. climate change origins such as

155 low precipitation, high temperature, limited volume of available water resources), society (e.g.

156 high population rate), economy (e.g. high pressure for increase in agricultural productions), and

157 policy (e.g. legislation enforced by national or federal responsible organisations). These probable

158 future events are defined here as plausible scenarios that are likely to happen but either affected

159 by external factors or made by those out of direct control of local organisations such as water

160 companies. Intervention strategies are defined here as technological and management measures

161 planned and implemented by local organisations (e.g. regional water utilities). The following

162 section outlines scenarios and strategies set out in the SD modelling. 
(a)

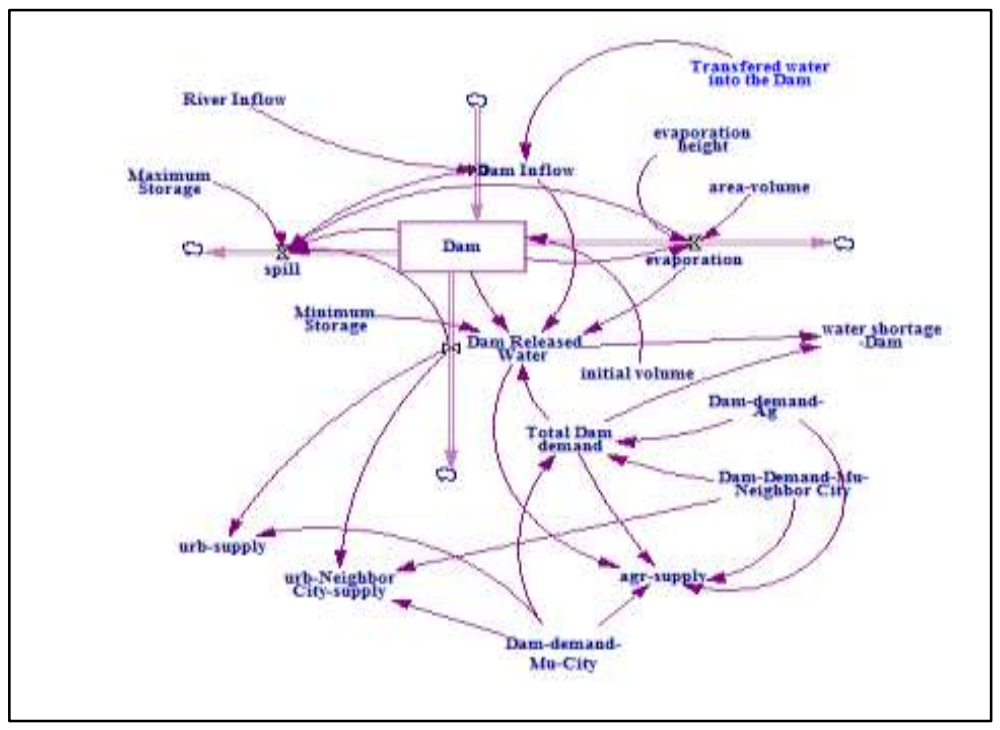

(c)

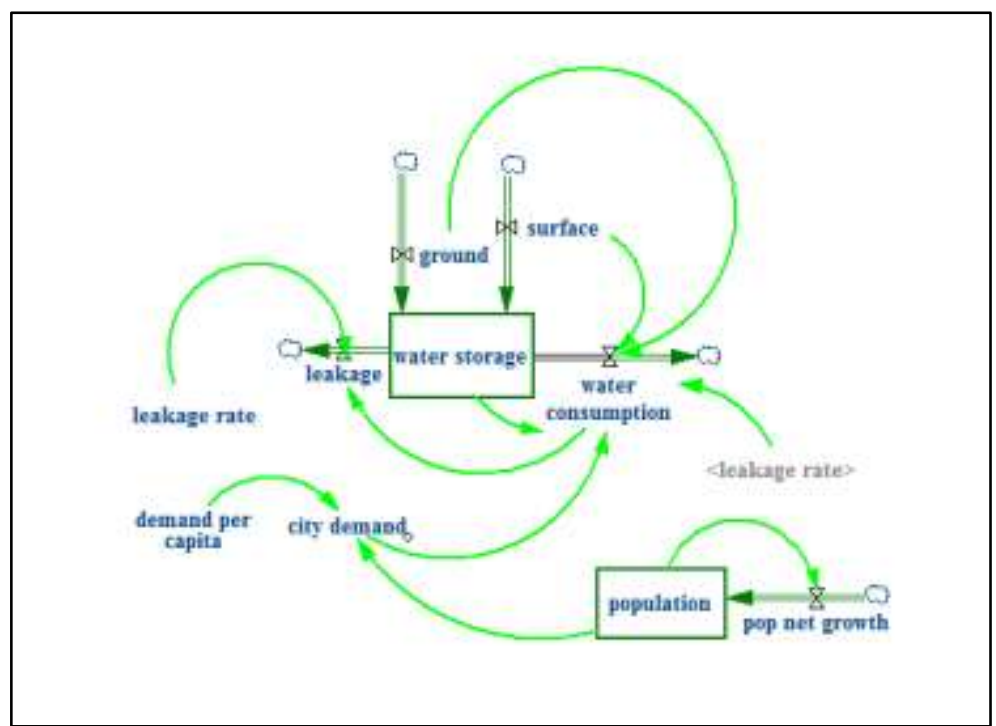

(b)

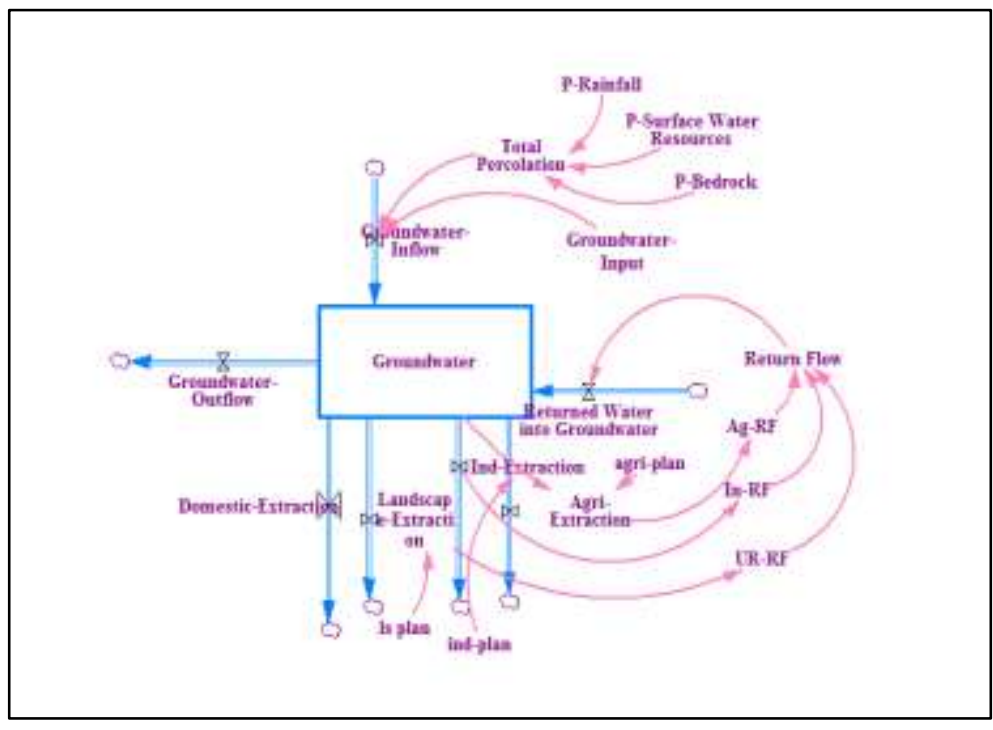

(d)

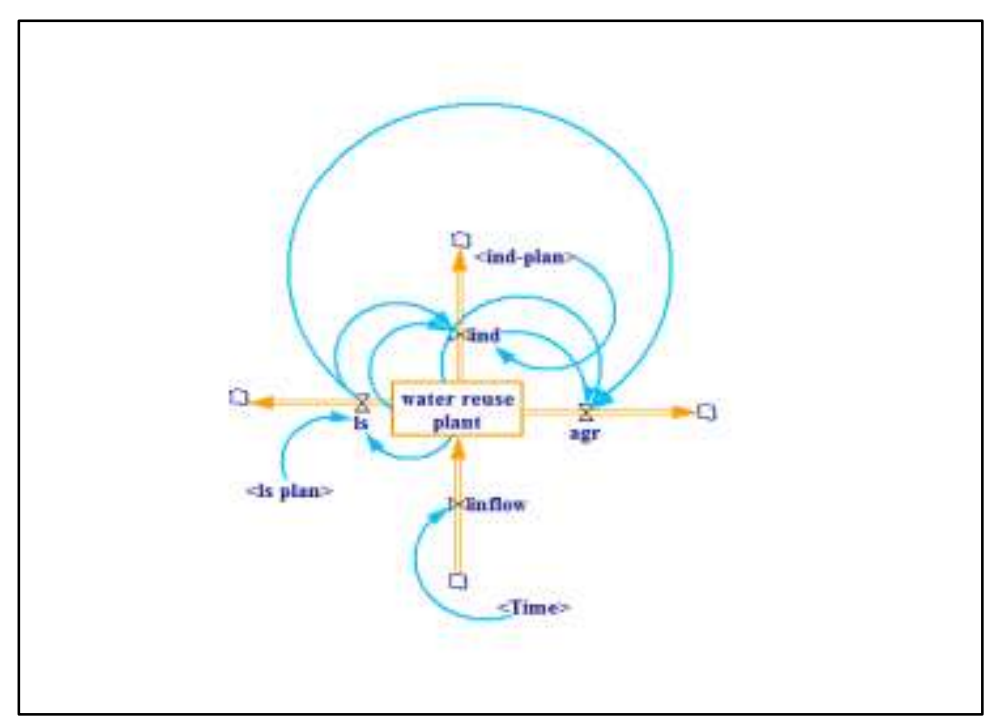

Figure 2: Main subsystems of the SD model: a) surface water, b) groundwater, c) service reservoir and water demand, d) water reuse 
166 Two types of scenario are defined here as Population Growth "PG" and GroundWater Extraction

167 Limits (Table 1). These scenario types are further divided into two rates of population growth and

168 three threshold limits for groundwater extraction. The two population growth rates are normal

169 (NPG) and rapid (RPG) representing current and highest predicted rate of population growth

170 projected to occur over a planning horizon, respectively. The three threshold limits of groundwater

171 extraction include (1) no threshold (NT) for abstraction although a minimum for the aquifer

172 volume needs to be defined to prevent complete depletion of the aquifer; (2) one minimum

173 threshold $(\mathrm{T})$ is set for the aquifer volume such that no agricultural demands are supplied when the

174 aquifer volume is less than the threshold; and (3) two thresholds (TT) are set for the aquifer volume

175 such that water demands are fully supplied for the volume more than upper threshold and partly

176 supplied to agriculture for volume between the two thresholds and no supply for volumes less than

177 the lower threshold. In the cases of the groundwater abstraction reaching the threshold limits, 178 agricultural demands are supplied either partially or fully depending on the aquifer volume relative

179 to the threshold limits. Ground water extraction limits inspired by UN Water (2015) defines any

180 limit that is considered as national laws of water conservation imposed by national or federal

181 government to control groundwater resources in a country. While no Threshold limit "NT"

182 scenario considers no control for groundwater abstraction by relevant organisations, one threshold

183 "T" and two thresholds "TT" scenarios resemble some restrictions on groundwater abstraction

184 imposed by responsible organisations. In total, six scenarios as shown in Table 1 can be made for

185 covering various composition of population growth rates and groundwater extraction limits. 


\begin{tabular}{clccc}
\hline $\begin{array}{c}\text { Scenario } \\
\text { type }\end{array}$ & \multicolumn{3}{c}{$\begin{array}{c}\text { Groundwater extraction } \\
\text { Limits }\end{array}$} \\
\hline & State of Scenario & No threshold "NT" & One threshold "T" & Two thresholds "TT" \\
\hline $\begin{array}{c}\text { Populatio } \\
\text { n growth } \\
\text { "PG" }\end{array}$ & $\begin{array}{l}\text { Rapid population } \\
\text { growth "RPG" }\end{array}$ & C\#1 & C\#2 & C\#3 \\
& $\begin{array}{l}\text { Normal population } \\
\text { growth "NPG" }\end{array}$ & C\#4 & C\#5 & C\#6 \\
\hline
\end{tabular}

\section{Intervention strategies}

191 Intervention strategies are defined as a combination of intervention options and policies set out by

192 water authorities for performance improvement of water systems over a long-term planning

193 horizon. Based on the investigation of potential intervention options in water systems, we analyse

194 three types of intervention strategies including agricultural water demand control, urban

195 wastewater reuse and water loss reduction in pipeline (Table 2). These strategies can also be highly

196 beneficial to preservation of water resources and lead to making more informed decisions for

197 domestic water supply. More specifically, agricultural irrigation typically accounts for the largest

198 water demand and hence any strategy derived from it would have a key role to minimise depleting

199 aquifers (Maliva \& Missimer 2012). "Agricultural Water Control" inspired by UN Water (2015)

200 represents the role of decision makers in regional authorities to make policies for water

201 preservation. The agricultural water control strategy is divided here into three further trends of

202 agricultural water demands (i.e. increasing, constant and decreasing) over the planning horizon.

203 "Water Demand Increase" indicates business as usual (i.e. do nothing) as water demand increases

204 proportional to population growth and demand increase for agricultural products. "Constant Water

205 Demand" and "Water Demand Decrease" can be considered as measures introduced by

206 stakeholders to harness agricultural water demands such as new water technologies, policies and

207 regulations set out for water allocation or restriction of water abstraction and public engagement 
208 and social awareness for efficient use of water supply. Treated wastewater reuse for non-potable

209 demands and water loss reduction in pipeline in urban water distribution systems are grouped here

210 as wastewater reuse \& leakage reduction strategy type for alleviation of the pressure on severely

211 depleting water resources. This strategy type is divided here into two further strategies defined in

212 Table 2 based on policies for wastewater reuse and improving the system efficiency. While "NWR-

213 LR" strategy assumes no wastewater reuse application is developed and pipeline water loss is

214 constant from service reservoirs over the planning horizon, "AWR-LR" strategy considers treated

215 wastewater reuse is allocated for non-potable use. In total, six combinations of intervention

216 strategies can be envisaged here (Table 2) that can be analysed for each of the six scenarios

217 introduced above for the assessment criteria outlined in the next section.

Table 2: Strategy types and numbering in the SD model

\begin{tabular}{llcc}
\hline \multicolumn{1}{c}{ Strategy type } & State of strategy & \multicolumn{2}{c}{ Agricultural water control } \\
\hline & $\begin{array}{c}\text { Water demand } \\
\text { increase }\end{array}$ & $\begin{array}{c}\text { Constant water } \\
\text { demand }\end{array}$ & $\begin{array}{c}\text { Water demand } \\
\text { decrease }\end{array}$ \\
\hline $\begin{array}{l}\text { Wastewater reuse \& } \\
\text { leakage reduction } \\
\text { "WR-LR" }\end{array}$ & $\begin{array}{l}\text { No wastewater reuse and water } \\
\text { loss reduction "NWR-LR" }\end{array}$ & S\#1 & S\#3 \\
\cline { 2 - 5 } & $\begin{array}{l}\text { Wastewater reuse and leakage } \\
\text { rate improvement "AWR-LR" }\end{array}$ & S\#2 & S\#4 \\
\hline
\end{tabular}

220 Key Performance Indicators (KPIs)

221 Five KPIs shown in Table 3 are selected to represent sustainability indices of water resources and

222 supply systems. They include Sustainability Index (SI), Reliability Index for domestic purpose

223 (RId), Reliability Index for agricultural purpose (RIag), Resource Stress Index (RSI) and Self-

224 Sufficiency Index (SSI). As the priority of water supply is first for domestic demands and then for

225 agricultural demands, domestic demands are expected to be fully supplied for all conditions (i.e.

$226 \mathrm{RId}=1$ ) while the impact of any water shortage is expected to be seen through water allocation of

227 agricultural demands that influence agricultural reliability index (RIag). RSI is a measure to 
228 demonstrate the growth rate of one region based on available water resources. SSI indicates

229 contribution of neighbouring water resources in water supply. The index shows the ratio of water

230 volume supplied by local water resources to water volume supplied by neighbouring water

231 resources.

232

Table 3: List of KPIs used in this study

\begin{tabular}{|c|c|c|c|}
\hline $\begin{array}{c}\text { Key } \\
\text { Performance } \\
\text { Indicators }\end{array}$ & Equations & Description & Reference \\
\hline $\begin{array}{l}\text { Sustainability } \\
\text { Index (SI) }\end{array}$ & $\begin{array}{cc}\text { If } & T A W>T W D \\
\text { SI }= & \frac{T A W-T W D}{T A W} \\
\text { If } & T A W \leq T W D \\
& \mathrm{SI}=0\end{array}$ & $\begin{array}{l}\text { TAW }=\text { total available water; TWD }=\text { total water demand; the ratio is always } \\
\text { between } 0 \text { and } 1 \text { in which } 0 \text { indicates no sustainability where there is no } \\
\text { adequate available water or available water is equal or less than water demand, } \\
\text { while for redundant supply, it is greater than zero. Thus, when TAW }>\text { TWD, } \\
\text { TWD equals to total water supply. The ratio is } 1 \text { for ideal case (i.e. max } \\
\text { sustainability when no water demand exists) }\end{array}$ & $\begin{array}{l}\text { Madani and } \\
\text { Mariño } \\
(2009)\end{array}$ \\
\hline $\begin{array}{l}\text { Reliability } \\
\text { Index for } \\
\text { domestic } \\
\text { purpose (RId) }\end{array}$ & $\mathrm{RId}=\frac{T W S d}{T W D d}$ & $\begin{array}{l}\text { TWSd }=\text { total domestic water supply and TWDd }=\text { total domestic water demand. } \\
\text { If there is no domestic water shortage, total water supply is equal to total water } \\
\text { demand }(\text { RId }=1 \text { ). For any domestic water shortage, RId }<1 \text {. }\end{array}$ & $\begin{array}{l}\text { Behzadian } \\
\text { et al. (2014) }\end{array}$ \\
\hline $\begin{array}{l}\text { Reliability } \\
\text { Index for } \\
\text { Agricultural } \\
\text { purpose } \\
\text { (RIag) }\end{array}$ & RIag $=\frac{T W S a g}{T W D a g}$ & $\begin{array}{l}\text { TWSag= total agricultural water supply; TWDag= total agricultural water } \\
\text { demand. If there is no agricultural water shortage, total agricultural supply } \\
\text { equals total agricultural demand (RIag }=1 \text { ). For agricultural water shortage, } \\
\text { RIag }<1 \text {. }\end{array}$ & $\begin{array}{l}\text { Behzadian } \\
\text { et al. (2014) }\end{array}$ \\
\hline $\begin{array}{l}\text { Resource } \\
\text { Stress Index } \\
\text { (RSI) }\end{array}$ & $\mathrm{RSI}=\frac{T W D}{T A W}$ & $\begin{array}{l}\text { TWD= total water demand; TAW= total available water. This index represents } \\
\text { potential growth based on the available water resources and evaluates the } \\
\text { sustainability of water supply based on water demand. }\end{array}$ & $\begin{array}{l}\text { Abadi et al. } \\
\text { (2014) }\end{array}$ \\
\hline $\begin{array}{l}\text { Self- } \\
\text { Sufficiency } \\
\text { Index (SSI) }\end{array}$ & $\mathrm{SSI}=\frac{T W S-T I W}{T W D}$ & $\begin{array}{l}\text { TWS = total water supply including recycled wastewater, harvested rainwater, or } \\
\text { desalinated water; TIW= total imported water from neighbouring catchments; } \\
\text { TWD= total water demand. A concept of urban water self-sufficiency has been } \\
\text { proposed as a measure of urban dependency on water imports. }\end{array}$ & $\begin{array}{l}\text { Rygaard et } \\
\text { al. (2011) }\end{array}$ \\
\hline
\end{tabular}

233

234 Compromise Programming (CP) method

235 The CP method belongs to a class of MCDA technique called "distance-based" methods. As KPIs

236 may have different units, normalised functions to ensure they have the same range (Behzadian and

237 Kapelan 2015). Multiple KPIs for each strategy are converted to one distance function and

238 strategies are then ranked according to these distances. Without loss of generality, assuming all

239 criteria are maximising, the overall distance function for an intervention strategy with an 
240 evaluation function $\left(f_{i}\right)$, maximum absolute (ideal) value $\left(f_{i}^{*}\right)$, minimum absolute (anti-ideal)

241 value $\left(f_{i^{*}}\right)$, weight or relative importance $\left(w_{i}\right)$ for criterion $i$, a topological metric of $p$ and number

242 of KPIs equal to $n$ is calculated as below assuming that the scaling function is linear:

$$
\text { minimise } L_{p}=\left[\sum_{i=1}^{n}\left(w_{i}\left(f_{i}^{*}-f_{i}\right) /\left(f_{i}^{*}-f_{i^{*}}\right)\right)^{P}\right]^{1 / P}, w_{i}>0,1 \leq p \leq \infty
$$

243 Parameter $p$ changes from 1 to $\infty$ and it has higher sensitivity if it takes higher value. For the CP

244 used in the paper $p$ was equal to 2. $f_{i}$ belongs to a corresponding KPI calculated by the SD over

245 the planning horizon. $f_{i}^{*}$ and $f_{i^{*}}$ is the maximum and minimum value of the corresponding KPI

246 among all strategies analysed. The relative weights $\left(w_{i}\right)$ represent the importance of the KPI

247 usually determined based on expert opinions. The weights considered in the paper were all equal

248 to 1 due to the equal importance of the KPIs for decision makers.

\section{Case study and SD model calibration}

250 The methodology was demonstrated here on a real-world case study for water systems of the

251 Kerman Catchment located in the southeast of Iran (Figure 3). The SD model was developed for 252600 monthly timesteps (50 years) from Oct 1987 to Sep 2037. The first 300 timesteps (from Oct 2531987 to Sep 2012), i.e. 25-year historical data, were used for building the SD model, its calibration 254 and validation. The next 300 timesteps (from Oct 2012 to Sep 2037) were used as the planning 255 horizon to evaluate intervention strategies under plausible scenarios. The case study is located 256 within the arid climate with average annual precipitation of $138 \mathrm{~mm}$ based on the annual average 257 rainfall of the catchment. Figure 4a illustrates the monthly precipitation of the case study. 258 Available water resources in the case study (Table 4) are (1) groundwater in Aquifer \#1 and 259 Aquifer \#2 and (2) surface water in dam \#1 and dam \#2. Aquifer \#1 comprising 1,197 tube-wells, 
261 depleted significantly due to the extremely excessive water extraction in the recent decades with

262 an average of 1.2-metre drop per year (Figure 4b). Table 4 summarises annual water withdrawals

263 of available water resources and after completing the construction. The future population of

264 Kerman projected by Statistical Centre of Iran (2016) for the two scenarios is shown in Figure 4c

265 for 25 years of the simulation period between Oct 2012 and Sep 2037.

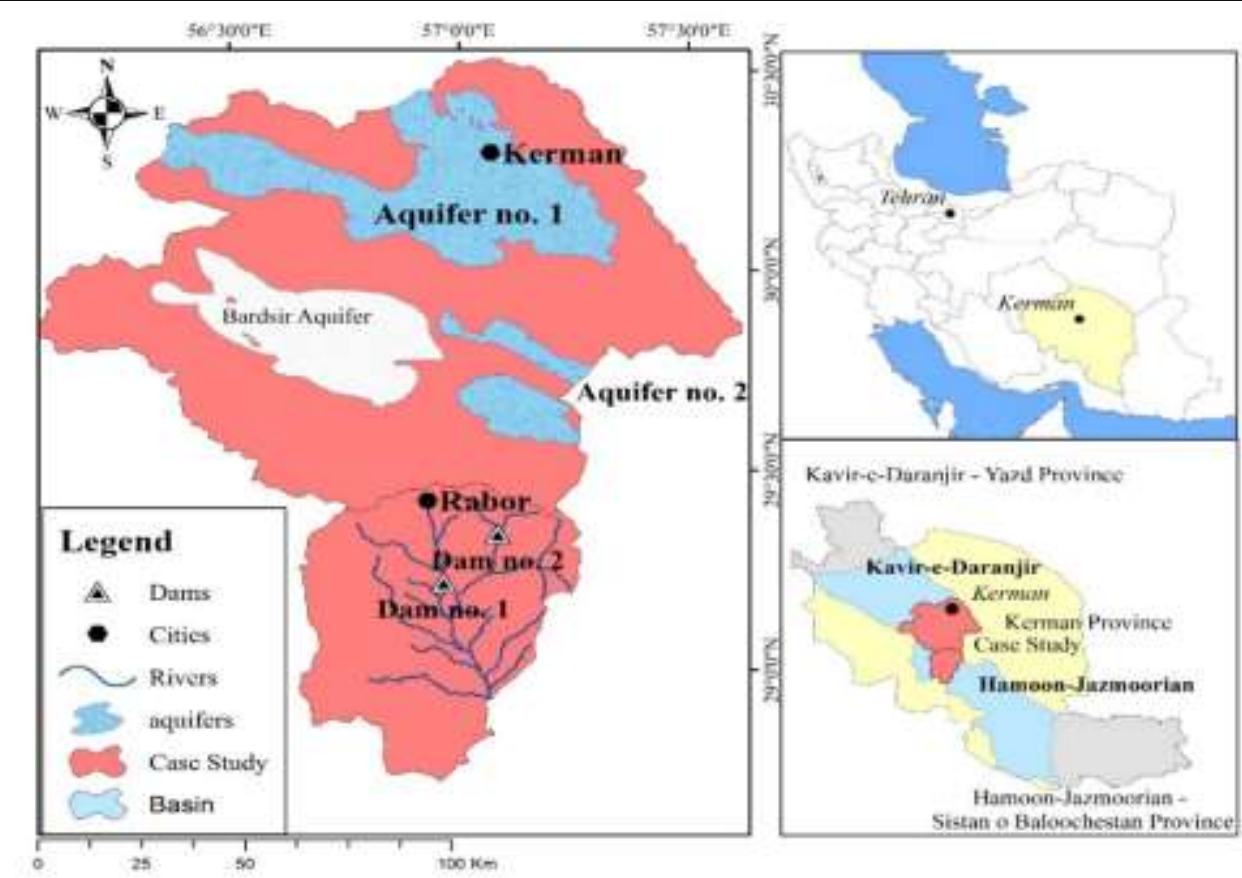

Figure 3: Layout of the case study

Table 4: Annual water withdrawals of available and future water resources in Million Cubic Meters (MCM)

\begin{tabular}{ccccc}
\hline & \multicolumn{2}{c}{ Groundwater resources } & \multicolumn{2}{c}{ Surface water resources** } \\
\cline { 2 - 5 } & Aquifer \#1 & Aquifer \#2 & Dam \#1 & Dam \#2 \\
\hline Agricultural & 240 & 0 & 6.11 & 0 \\
Domestic & 44.4 & $11^{*}$ & 24.16 & 20.1 \\
Industrial & 7.7 & 0 & 0 & 0 \\
Landscape & 0.9 & 0 & 0 & 0 \\
Rabor Region & 0 & 0 & 2 & 0 \\
Total & 293 & 11 & 32.27 & 20.1 \\
\hline
\end{tabular}

$270 *$ water supply after Oct 2004

$271{ }^{* * *}$ water supply after Oct 2018 

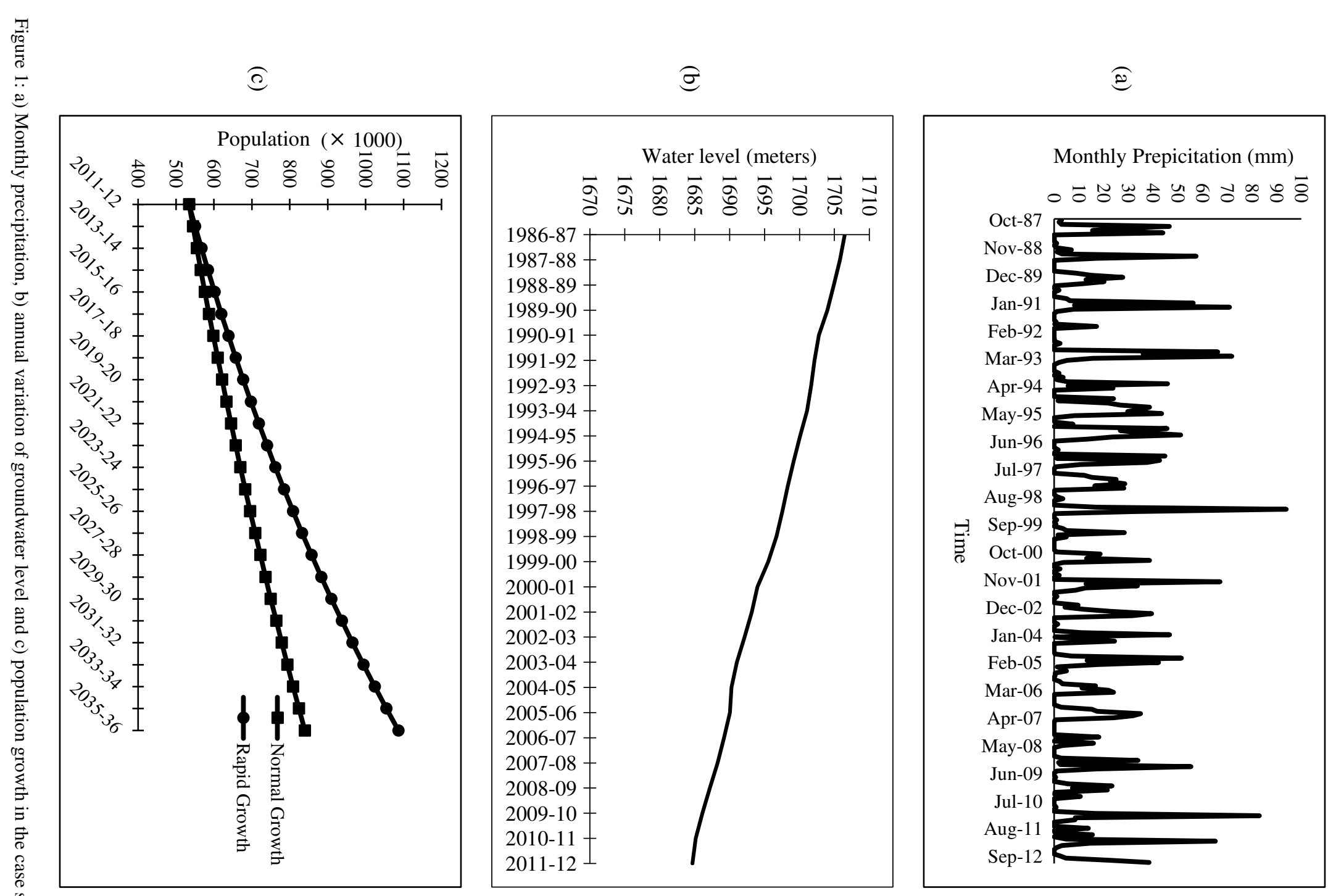
274 The calibration result for the first 300 timesteps is shown in Figure 5a. The close agreement of 275 groundwater volume between the observed data and model output indicates a good model 276 calibration (see statistical tests in Supplementary S.2). Water demands are supplied by 277 groundwater resources only within timestep 301-373 (Oct 2012 to Oct 2018) while the surface 278 water resources are used from timestep 373 (Oct 2018). At the early years of surface water 279 operation, dam \#1 filled up rapidly (Figure 5b) and significant spills occurred due to large inflows 280 (Figure 5d) while reservoir volume gradually reduced as inflow decreased significantly within the 281 remaining timesteps of the planning horizon (Figure 5c).

282 The threshold of "groundwater extraction limits" was defined as: 1) 10 MCM set for scenarios 283 with no threshold, i.e. $\mathrm{C \# 1}$ and $\mathrm{C \# 4}$, as the minimum volume avoiding complete depletion of the 284 aquifers; 2) $700 \mathrm{MCM}$ threshold set for scenarios with one threshold, i.e. C\#2 and C\#5, as 285 agricultural water demands were supplied when the aquifer volume is greater than this amount; 286 and 3) for scenarios with two thresholds, i.e. C\#3 and C\#6, $1000 \mathrm{MCM}$ for the upper threshold and $287700 \mathrm{MCM}$ for the lower threshold of the aquifer volume. Agricultural water supply at timestep t $288\left(A S_{t}\right)$ for scenarios with two thresholds is calculated based on Eq. (2):

$$
A S_{t}=\left\{\begin{array}{lrr}
A D_{t} & \text { if } & V a_{t}-A D_{t} \geq 1000 \\
\alpha \times A D_{t} & \text { if } & 1000>V a_{t}-A D_{t}>700 \\
& \alpha=\frac{V a_{t}-D D_{t}-I D_{t}-L D_{t}-700}{1000-700}<1 \\
& \text { if } & 700>V a_{t}-A D_{t}
\end{array}\right.
$$

289 where $V a_{t}=$ the aquifer volume at time $t(\mathrm{MCM}), A D_{t}=$ the agricultural demand at timestep $t(\mathrm{MCM})$, $290 D D_{t}, I D_{t}, L D_{t}=$ domestic demand, industrial demand and landscape demand at time $t$, respectively 291 (MCM). Agricultural water demands consider the relevant strategies (i.e. increase, constant or 292 decrease) between timestep 301-600 (Oct 2012 and Sep 2037). Agricultural water demand strategy 
293 for constant rate considers the same water demands as water year 2011-12 for the entire remaining 294 timesteps. However, "wastewater reuse \& leakage reduction" strategies "WR-LR" considers to be 295 in place from timestep 400 (Jan 2021). "No wastewater reuse \& leakage reduction" strategy 296 considers a constant rate of water loss (35\% of total domestic water supply) for all timesteps while 297 "wastewater reuse and leakage rate improvement" strategy assumed that water loss reduced 298 uniformly from $35 \%$ to $20 \%$ from timestep 400.

(a)

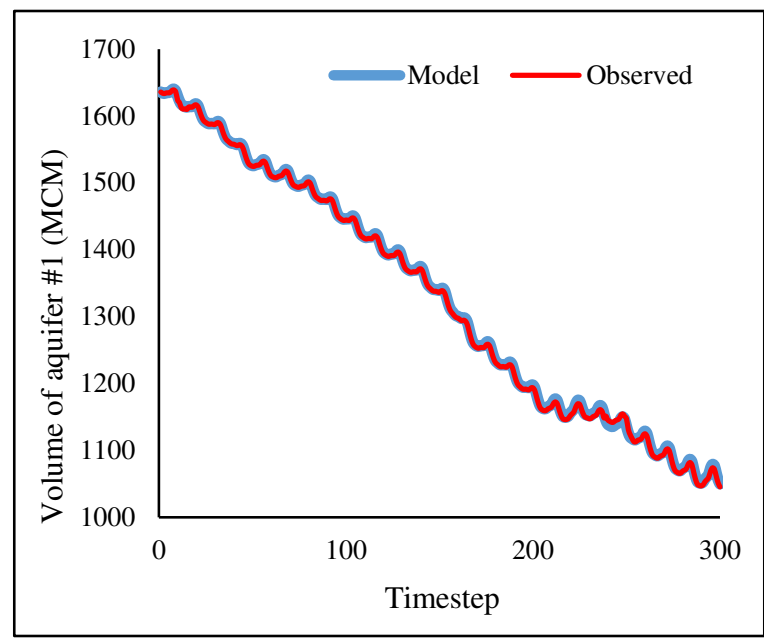

(c)

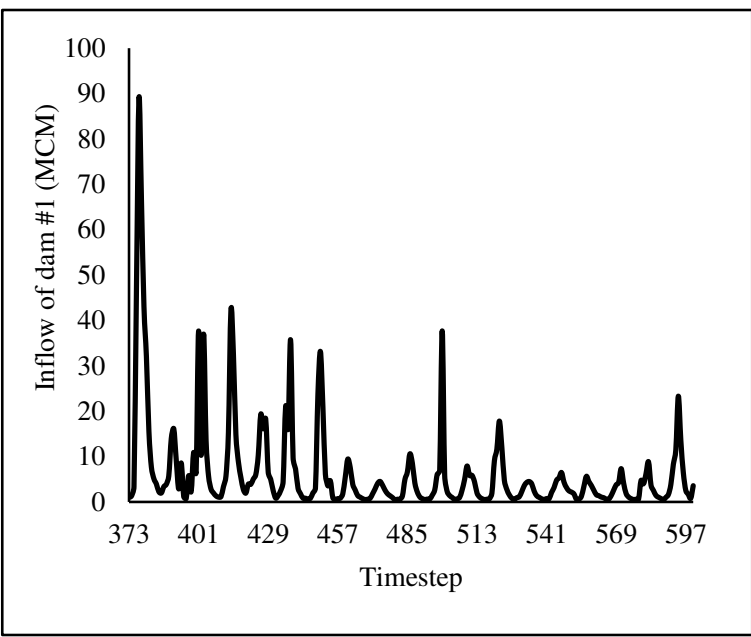

(b)

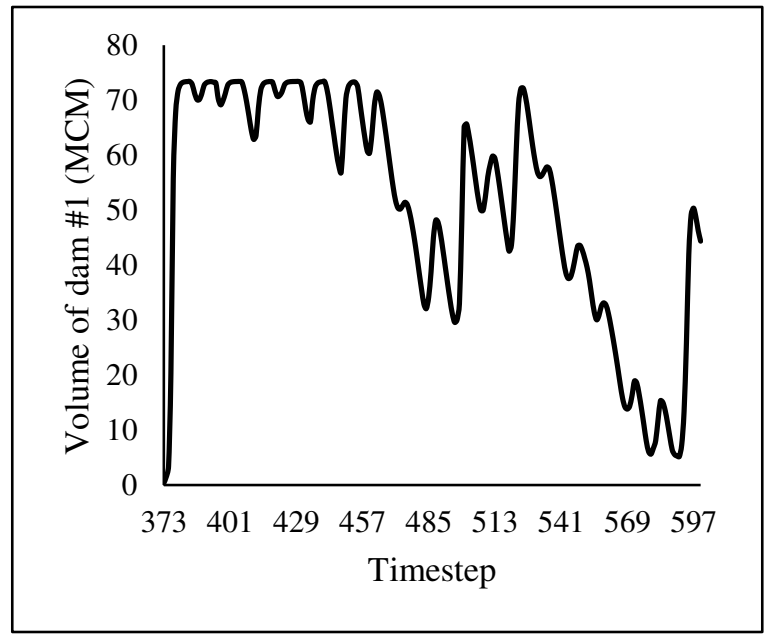

(d)

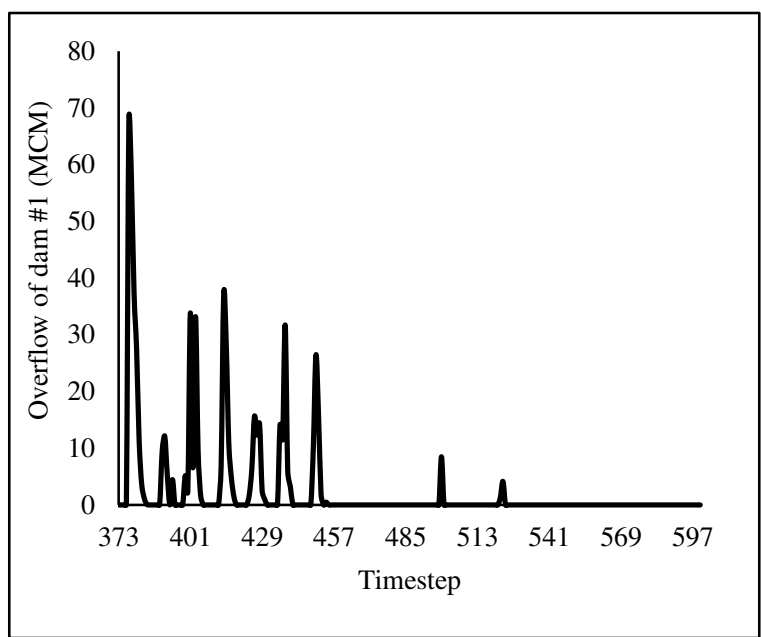

Figure 2: a) Water volume in aquifer \#1 for observed data and model output; variables of dam \#1 for b) reservoir volume, c) inflow, d) overflow. 
302 Figure 6 summarises the timeframe for all scenarios, strategies, and water resources over the entire

303600 timesteps. As can be seen, all scenarios and strategies except "wastewater reuse \& leakage

304 reduction" strategy "WR-LR" starts from timestep 301 (Oct 2012) when planning horizon starts

305 while the "WR-LR" strategy starts from timestep 401 (Feb 2021) and new surface water

306 transfer/resource (dam \#1) was added from timestep 373 (Oct 2018). The model developed here

307 was also analysed under extreme condition tests to control the model output values under limited

308 conditions (see supplementary S.3).

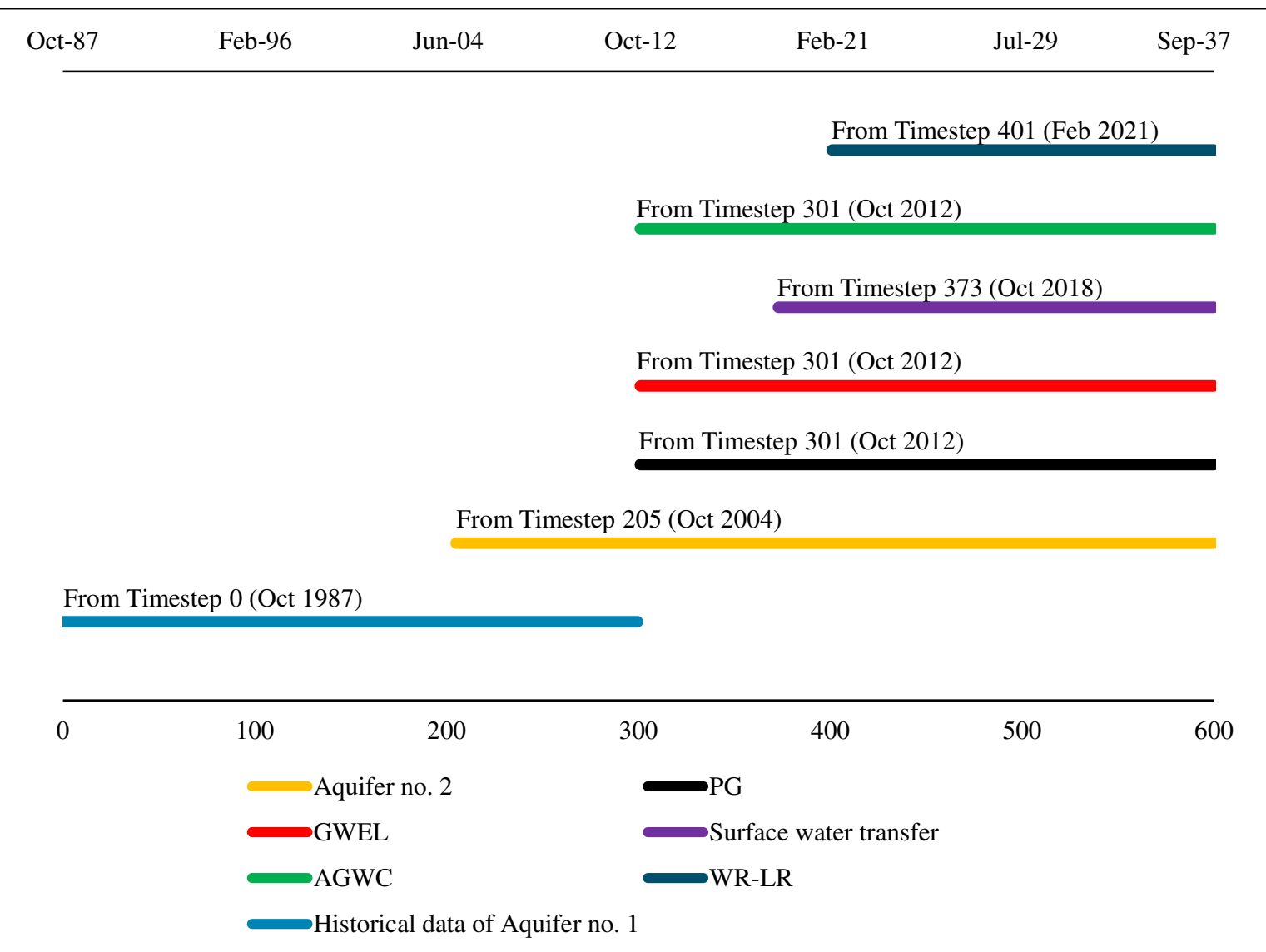




\section{Results and discussion}

314 After the SD model calibration with the historic data, the long-term performance of the

315 intervention strategies was evaluated for each plausible scenario. Figure 7 shows the variation of

316 two KPIs (SSI and RId) for some strategies and scenarios over the simulation period. The variation

317 of the SSI in Figure 7a illustrates how water supply is dependent on local and external

318 (neighbouring) water resources. The SSI is 1 for the first 205 timesteps when aquifer \#1 is the only

319 water resource but the index drops twice significantly due to adding the two new water resources:

320 (1) aquifer \#2 in timestep 205 (Oct 2004) following a slightly increasing trend with fluctuations

321 which are the same for all strategies and (2) dam \#1 in timestep 373 (Oct 2018) following a slightly

322 steeper increasing trend with fluctuations. Both new water resources (aquifer \#2 and dam \#1) are

323 allocated for domestic water demands (see Table 3). As can be seen in the figure, domestic water

324 demands are more supplied from aquifer \#1 in rapid population growth "RPG" scenarios regardless

325 of the strategy type.

326 The performance of all strategies discussed here are given only for aquifer \#1 as the main water

327 resource of the study. Figure 8 shows the variation of volume in aquifer \#1 for all strategies in

328 each scenario. As can be seen in figures $8 \mathrm{a}$ and $8 \mathrm{~b}$, for both scenarios with no threshold for

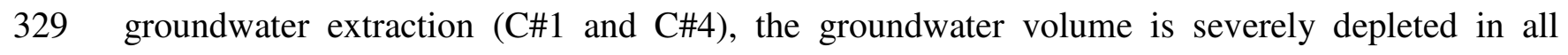

330 strategies except strategies S\#5 and S\#6 by the end of the planning horizon. This is due to the large

331 groundwater extraction from the aquifer in all strategies except S\#5 and S\#6 which have positive

332 effect on groundwater volume. This is due to the sustainable yield of groundwater in both strategies

333 with "Water Demand Decrease" (S\#5 and S\#6) that lead to reclamation of groundwater by reducing

334 the extraction volume. The impact of "wastewater reuse and leakage reduction" strategies is also 
335 minor for conservation of groundwater resources in these two scenarios. Furthermore, there is no 336 sensible impact of different population growth rates on the groundwater volume in these scenarios.

(a)

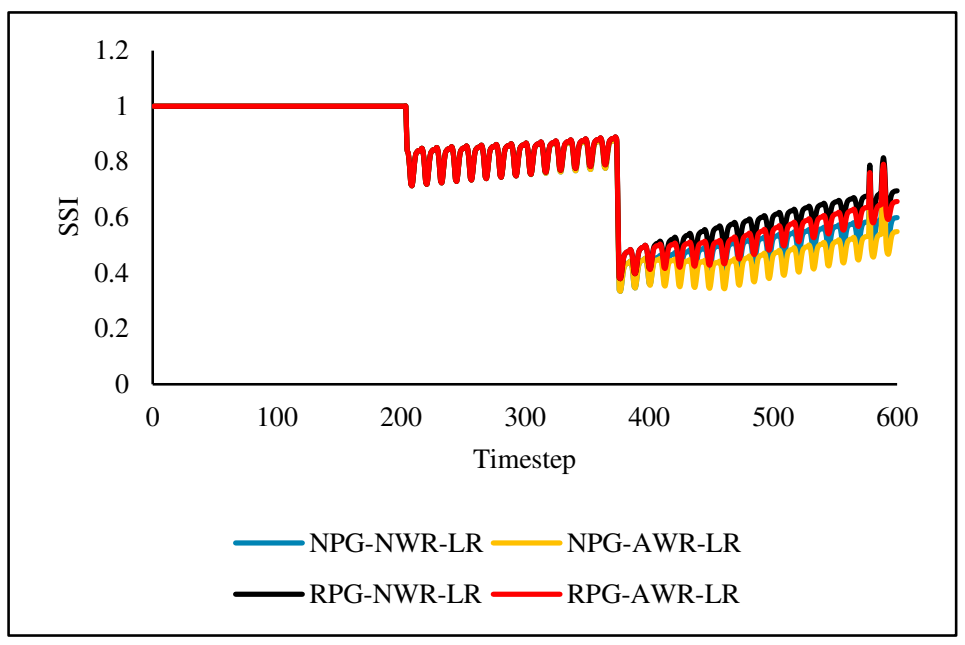

(b)

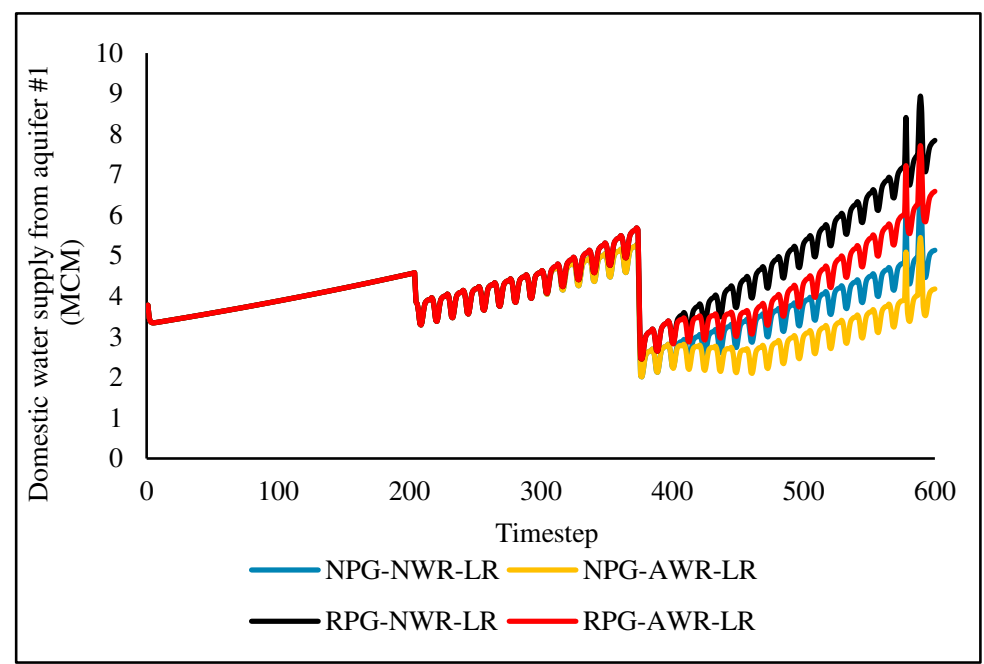




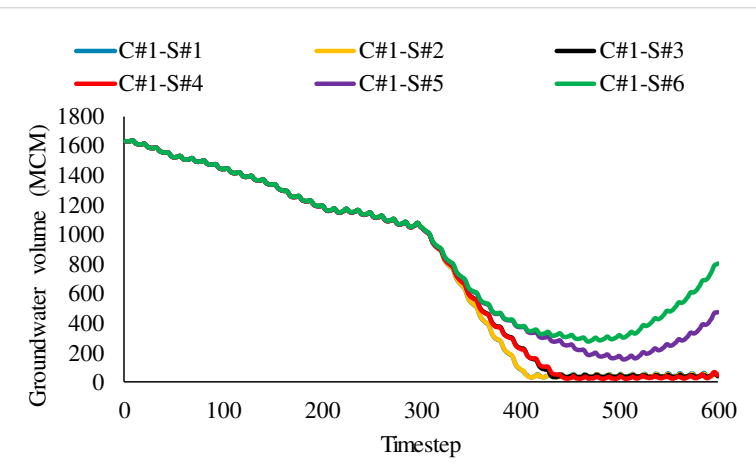

(a)

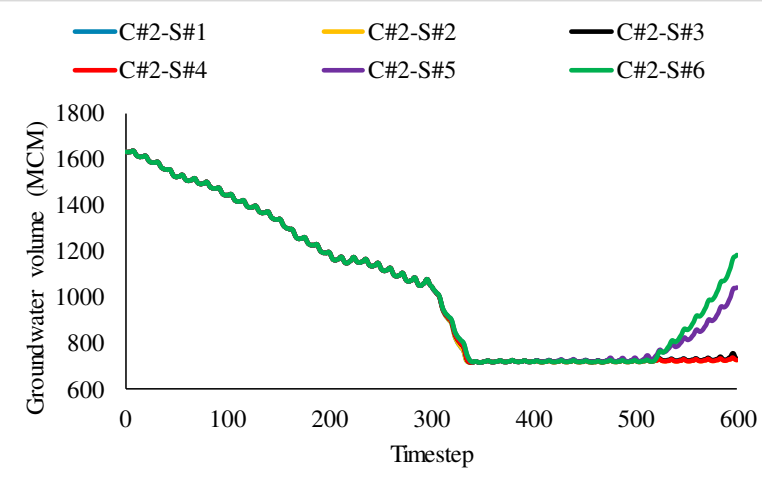

(c)

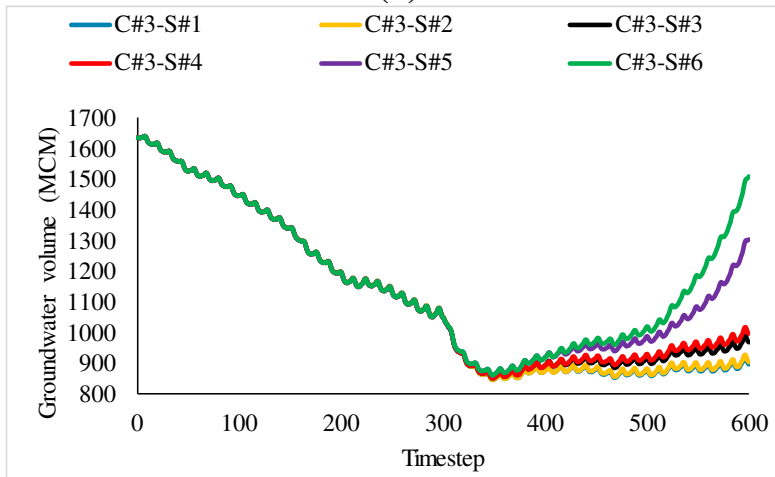

(e)

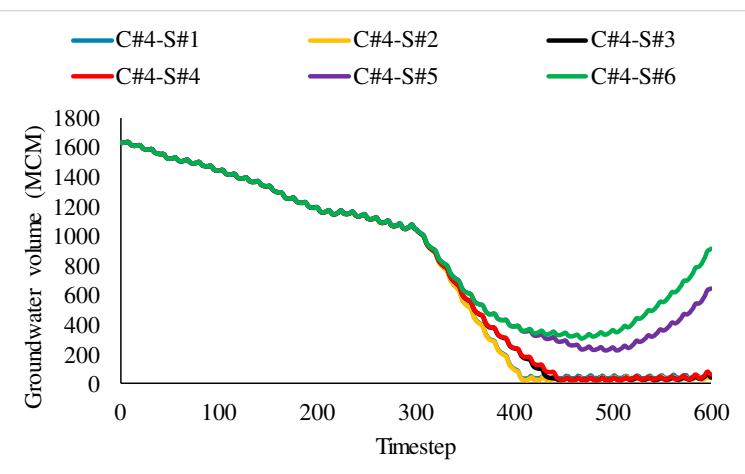

(b)

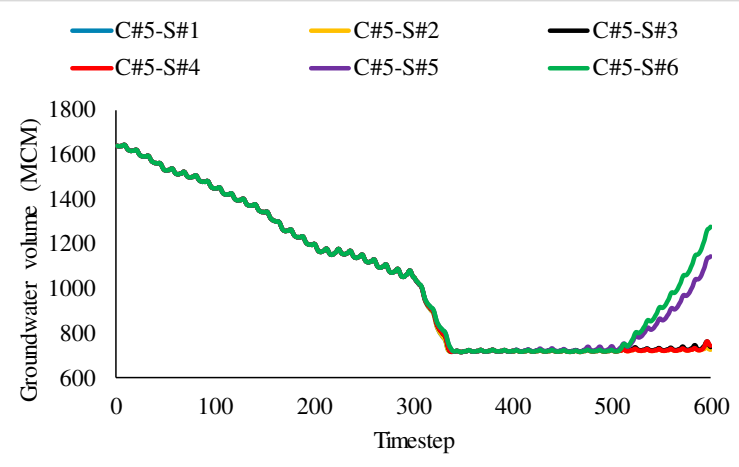

(d)

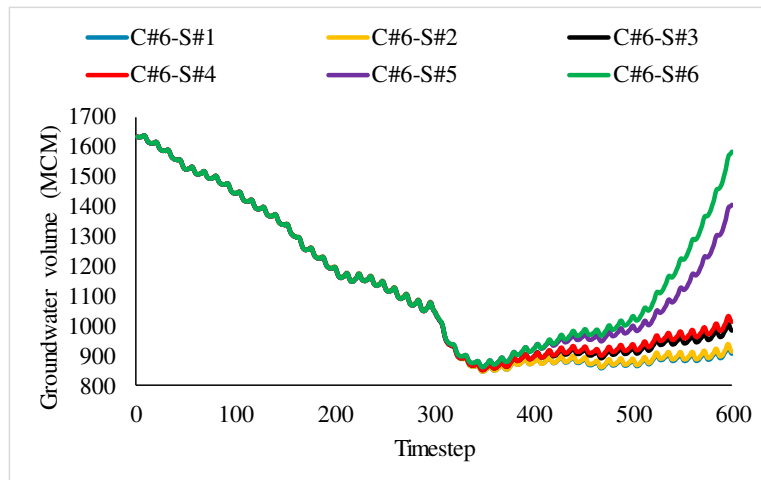

(f)

Figure 5: Variation of volume in aquifer \#1 for all strategies and scenario a) C\#1, b) C\#4, c) C\#2, d) C\#5, e) C\#3and f) C\#6

341 For the scenario with one threshold (C\#2 and C\#5) in figures 8c and 8d, the performance of all

342 strategies and their impact on the preservation of groundwater resources are quite similar to those

343 in the previous two scenarios (C\#1 and C\#4). In other words, minor impact of "wastewater reuse

344 and leakage reduction" strategies on groundwater resources recovery and similar response of all

345 strategies in both population growth scenarios indicate that these scenarios and strategies can be 
346 discarded for the management of groundwater resources conservation when either no threshold or

347 one threshold of groundwater abstraction is the prevailing scenario. On the other hand, strategies

348 S\#5 and S\#6 (agricultural demand decrease), can again recover groundwater resources coming off

349 the threshold limit of $700 \mathrm{MCM}$ at the end of the planning horizon. The only concern is that there

350 is no alarm for water extraction from the aquifer in these two scenarios until the aquifer volume

351 dropped to $700 \mathrm{MCM}$. As a result, water withdrawal is sharply depleting groundwater resources

352 until reaching the threshold level between timesteps 347 (Sep 2016) and 516 (Sep 2030). The

353 agricultural water extraction is gradually decreased until it can lead to the recovery of the

354 groundwater by the end of the planning horizon. Hence, excessive agricultural water extraction is

355 considered as the main unavoidable consequences of this depletion.

356 For the scenarios with two threshold limits (C\#3 and C\#6) in figures 8e and 8f, groundwater

357 resources are sustainably recovered in almost all strategies although the recovery rate varies

358 significantly between strategies with different agricultural water withdrawal. Despite the

359 groundwater resources recovery in all strategies, groundwater extraction may not be able to fully

360 supply agricultural demands in some periods due to the restrictions imposed by the two threshold

361 limits. However, it is evident that the aquifer is likely to be more sustainable for all strategies when

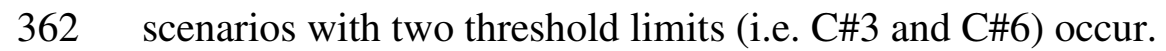

363 Figure 9 shows the recovery rate of groundwater in all scenarios and strategies analysed (i.e.

364 difference of the aquifer volume between the minimum value and the last timestep). As can be

365 seen in figure 9a, in the case of scenarios with either no threshold (C\#1, C\#4) or one threshold

366 (C\#2, C\#5), the strategies involving agricultural water demand decrease (S\#5, S\#6) can

367 significantly recover the groundwater volume with an average recovery rate of $130 \%$. However,

368 other strategies of agricultural groundwater abstraction (i.e. constant rate S\#3, S\#4 and increase 
370 also shows for the scenarios with two threshold limits of groundwater extraction, all strategies can

371 sustainably recover the aquifer with an average recovery rate of $33 \%$.

(a)

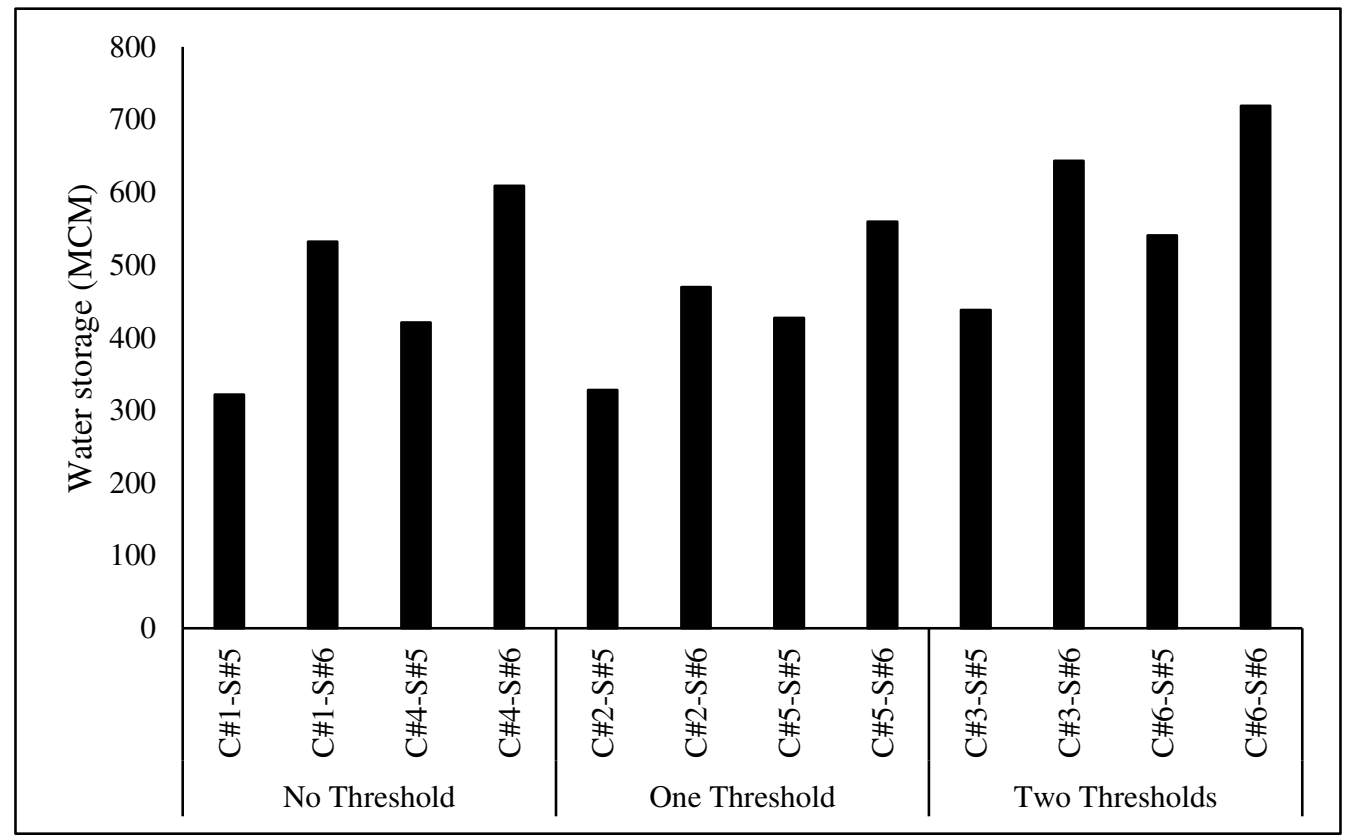

(b)

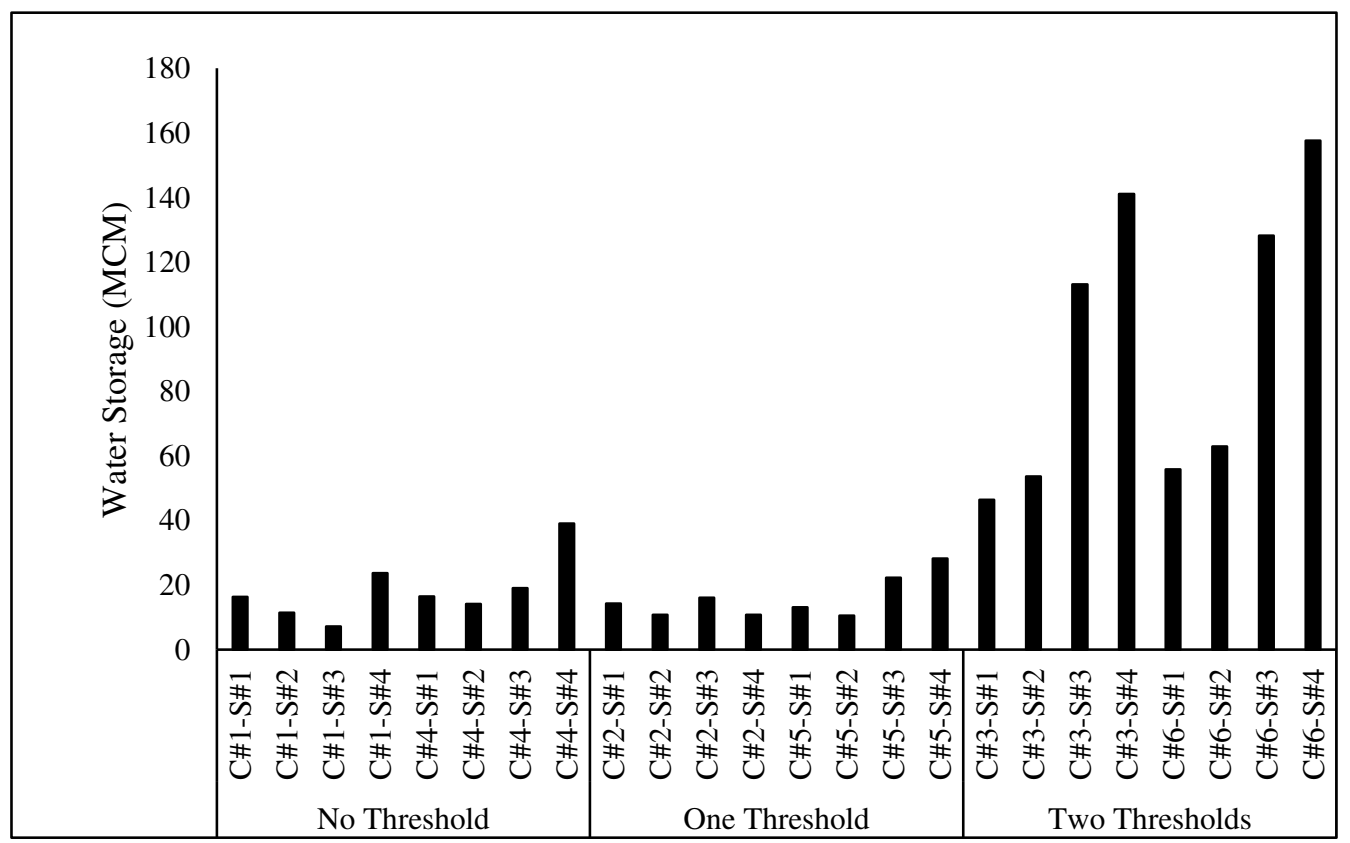

Figure 9: The volume difference of aquifer \#1 between the timestep with minimum volume and timestep 600 for strategies with a) water demand decrease S\#5 S\#6 and b) water demand constant S\#3 S\#4 and water demand increase S\#1 S\#2 
375 Comparing the two types of scenarios shows the impact of population growth on the aquifer

376 volume is much less than groundwater threshold. More specifically, the difference of the impact

377 of groundwater recovery between the scenarios with normal and rapid population growths is an

378 average of $11 \%$ compared to $79 \%$ for the difference of groundwater recovery rates between the

379 groundwater extraction limits with no threshold and two threshold limits. However, when

380 comparing the two population growth scenarios, the results show the rapid population growth has

381 more influence on depleting groundwater aquifer than the normal population growth in all

382 strategies. Similarly, the influence of strategies with wastewater reuse and leakage reduction

383 category on groundwater volume is almost negligible compared to those strategies without

384 wastewater reuse and leakage reduction.

386 Ranking strategies

387 The CP method is used here to rank the six strategies based on the four KPIs for each scenario.

388 Table 5 gives the overall distance function of KPIs calculated by Eq. (1) for each strategy over the

389 planning horizon and corresponding rankings of strategies for each scenario. The calculation of

390 the distance function in Eq. (1) assumes parameter $P$ is equal to 2 and all weights are equal to 1

391 and extreme (ideal) values $\left(f_{i}^{*}\right)$ are maximum of SI, RId and RIag and minimum of RSI. The

392 consistency of overall rank for all strategies across the six scenarios indicates the robustness of the

393 performance for the strategies regardless of occurring any scenario. The order of priority of

394 strategies can also be defined as (1) agricultural water demand control; and (2) wastewater reuse 395 and leakage loss reduction. 
Table 5: Overall distance function of the CP method for KPIs in each strategy and ranking of strategies in each scenario

\begin{tabular}{|c|c|c|c|c|c|c|c|}
\hline \multirow{2}{*}{ Scenarios } & \multirow{2}{*}{ KPIs } & \multicolumn{6}{|c|}{ Strategies } \\
\hline & & $\mathrm{S} \# 1$ & $\mathrm{~S} \# 2$ & S\#3 & $\mathrm{S} \# 4$ & S\#5 & S\#6 \\
\hline \multirow{5}{*}{$\mathrm{C \# 1}$} & SI & 0.38 & 0.422 & 0.466 & 0.563 & 0.917 & 0.951 \\
\hline & RId & 0.805 & 0.778 & 0.879 & 0.914 & 1 & 1 \\
\hline & RSI & 0.621 & 0.377 & 0.535 & 0.361 & 0.083 & 0.048 \\
\hline & RIag & 0.767 & 0.747 & 0.85 & 0.9 & 1 & 1 \\
\hline & Rank & 6 & 5 & 4 & 3 & 2 & 1 \\
\hline \multirow{5}{*}{$\mathrm{C \# 2}$} & SI & 0.951 & 0.956 & 0.958 & 0.964 & 0.967 & 0.972 \\
\hline & RId & 0.689 & 0.695 & 0.802 & 0.837 & 0.915 & 0.959 \\
\hline & RSI & 0.049 & 0.029 & 0.042 & 0.029 & 0.033 & 0.025 \\
\hline & RIag & 0.626 & 0.644 & 0.755 & 0.807 & 0.894 & 0.954 \\
\hline & Rank & 6 & 5 & 4 & 3 & 2 & 1 \\
\hline \multirow{5}{*}{$\mathrm{C \# 3}$} & SI & 0.959 & 0.963 & 0.966 & 0.971 & 0.974 & 0.978 \\
\hline & RId & 0.646 & 0.644 & 0.747 & 0.765 & 0.86 & 0.876 \\
\hline & RSI & 0.041 & 0.024 & 0.034 & 0.022 & 0.026 & 0.018 \\
\hline & RIag & 0.579 & 0.589 & 0.69 & 0.72 & 0.826 & 0.848 \\
\hline & Rank & 6 & 5 & 4 & 3 & 2 & 1 \\
\hline \multirow{5}{*}{$\mathrm{C \# 4}$} & SI & 0.409 & 0.448 & 0.527 & 0.614 & 0.937 & 0.957 \\
\hline & RId & 0.798 & 0.775 & 0.922 & 0.961 & 1 & 1 \\
\hline & RSI & 0.592 & 0.359 & 0.473 & 0.352 & 0.063 & 0.043 \\
\hline & RIag & 0.77 & 0.753 & 0.91 & 0.957 & 1 & 1 \\
\hline & Rank & 6 & 5 & 4 & 3 & 2 & 1 \\
\hline \multirow{5}{*}{$\mathrm{C \# 5}$} & SI & 0.952 & 0.957 & 0.96 & 0.964 & 0.969 & 0.973 \\
\hline & RId & 0.7 & 0.706 & 0.818 & 0.85 & 0.924 & 0.961 \\
\hline & RSI & 0.048 & 0.029 & 0.04 & 0.029 & 0.031 & 0.024 \\
\hline & RIag & 0.651 & 0.668 & 0.784 & 0.828 & 0.908 & 0.954 \\
\hline & Rank & 6 & 5 & 4 & 3 & 2 & 1 \\
\hline \multirow{5}{*}{ C\#6 } & SI & 0.96 & 0.964 & 0.968 & 0.972 & 0.975 & 0.979 \\
\hline & RId & 0.652 & 0.652 & 0.761 & 0.777 & 0.869 & 0.881 \\
\hline & RSI & 0.04 & 0.023 & 0.032 & 0.022 & 0.025 & 0.018 \\
\hline & RIag & 0.601 & 0.612 & 0.718 & 0.744 & 0.842 & 0.858 \\
\hline & Rank & 6 & 5 & 4 & 3 & 2 & 1 \\
\hline
\end{tabular}

399 Despite the same rank of strategies in different scenarios, there are significant differences in

400 groundwater volume between similar strategies of different scenarios. According to Table 5, the

401 roles of the national water organisation and regional water authorities can be highlighted in policy 
402 making for water allocation and resources conservation in a region. Obviously, appropriate

403 national regulations (e.g. groundwater extraction limits) can facilitate the process of decision

404 making by the regional authorities. For example, scenarios with two groundwater thresholds (C\#3,

405 C\#6) are likely to preserve the groundwater resources when it is combined with the "water demand

406 decrease" strategies (S\#5, S\#6) or "constant water demand" strategies (S\#3, S\#4) made by the

407 regional authorities. However, under the scenario with no threshold limits (C\#1, C\#4), only the

408 strictest strategies of agricultural water withdrawal (S\#5, S\#6) made by regional water authorities

409 can lead to the preservation of groundwater resources. As groundwater resources are the main

410 water resources of arid and semi-arid areas, the amount of water allocation for each sector

411 (domestic, industry, agriculture, landscape, and services) signifies the regional decision making

412 due to the natural limitations of arid lands in supplying water. In this situation, the regional

413 decision-makers must determine domestic water demand as the priority of water supply to avoid

414 transferring the tensions of water scarcity towards the local inhabitants.

\section{Conclusions}

417 This paper conducted a scenario-based assessment of potential intervention strategies for long-

418 term planning of complex water resources and supply systems with respect to multiple

419 sustainability criteria by using the SD and MCDA modelling approaches. The model was

420 demonstrated on a real-world case study that was calibrated for historic 25-year data and simulated

421 for long-term strategic planning for the next 25-year period. Results show scenario-based analysis

422 can provide the most appropriate strategies leading to long-term sustainability of water resources

423 for each scenario imposed on the water systems. The following can also be concluded from the

424 results discussed here: 
1. When dealing with either no threshold or one threshold of groundwater extraction limit, the only effective strategies for sustainable groundwater management are those involving agricultural water demand decrease over the planning horizon while other strategies of

4. Scenarios with any population growth rates have negligible impact on groundwater

2. The groundwater resources can be sustainable in almost all analysed strategies only when scenarios with two threshold limits occur although with variable recovery rates.

3. "Wastewater reuse and leakage reduction" strategies have minor impacts for groundwater resources conservation compared to agricultural water abstraction strategies. conservation and no impact on ranking of strategies but scenarios with strict groundwater extraction limits (one or two thresholds) have major impact on groundwater conservation although again no impact on ranking strategies.

5. National organisations can have pivotal role for setting out regulations for water resources conservation and sustainability, but regional authorities can select suitable strategies based on the available scenario to either achieve sustainable performance of water resources or avoid the adverse consequences of unsustainable resources.

442 Institutional support should also be implemented to prevent the undesired consequences of 443 ineffective and unsustainable exploitation of shared public resources. Aligning the long-term 444 interests of people and governmental principals through efficient institutions is a crucial issue, 445 requiring continuous monitoring as well as positive interactions between the governments and the 446 public to address the dynamics and complexities of sustainable water supply. These social science 447 factors need to be included in future studies of intervention strategies and plausible scenarios. 


\section{Declarations}

$449 \quad$ Funding

450 No funds, grants, or other support was received.

451 Conflicts of interest/Competing interests

452 The authors have no conflicts of interest to declare that are relevant to the content of this article.

453 Availability of data, code and material

454 The data and code used in the article is available upon the request.

\section{Consent for publication}

456 The authors give explicit consent to submit this article for review and publication.

References

Abadi, L.S.K., Shamsai, A., Goharnejad, H. 2014. An Analysis of the Sustainability of Basin Water Resources using Vensim Model, KSCE Journal of Civil Engineering, 19(6), 1941-1949, https://doi.org/10.1007/s12205-014-0570-7. Arfanuzzaman, M., Atiq-Rahman, A. 2017. Sustainable water demand management in the face of rapid urbanization and ground water depletion for social-ecological resilience building, Global Ecology and Conservation, 17, 9-22,

$462 \quad$ https://doi.org/10.1016/j.gecco.2017.01.005.

463 Baki, S., Rozos, E., Makropoulos, C. 2018. Designing water demand management schemes using a socio-technical 464 modelling approach, Science of the total environment, 622-623, 1590-1602, 465 https://doi.org/10.1016/j.scitotenv.2017.10.041.

Behzadian, K. Kapelan, Z. 2015. Advantages of integrated and sustainability based assessment for metabolism based strategic planning of urban water systems, Science of The Total Environment, 527-528, 220-231, $468 \quad$ https://doi.org/10.1016/j.scitotenv.2015.04.097.

469 Behzadian, K., Kapelan, Z., Govindarajan, V., Brattebø, H., \& Sægrov, S. 2014. WaterMet²: a tool for integrated analysis of sustainability-based performance of urban water systems. Drinking Water Engineering and Science, 7 ,

471 63-72, http://dx.doi.org/10.5194/dwes-7-63-2014,

472 Fang, C., Cui, X., Li, G., Bao, C., Wang, Z., Ma, H., Sun, S., Liu, H., Luo, K., Ren, Y. 2019. Modeling regional 473 sustainable development scenarios using the Urbanization and Eco-environment Coupler: Case study of Beijing474 Tianjin-Hebei urban agglomeration, China, Science of the total environment, 689, 820-830, 475 https://doi.org/10.1016/j.scitotenv.2019.06.430. 
Hassanzadeh, E., Zarghami, M. and Hassanzadeh, Y., 2012. Determining the main factors in declining the Urmia Lake level by using system dynamics modeling. Water Resources Management, 26(1), 129-145, https://doi.org/10.1007/s11269-011-9909-8

Hosseini, S. M., Parizi, E., Ataie-Ashtiani, B., Simmons, C. T. 2019. Assessment of sustainable groundwater resources management using integrated environmental index: Case studies across Iran, Science of the total environment, 676, 792-810, https://doi.org/10.1016/j.scitotenv.2019.04.257.

Jia, X., O’Connor, D., Hou, D., Jin, Y., Li, G., Zheng, C., Ok, Y. S., Tsang, D. C. W., Luo, J. 2019. Groundwater depletion and contamination: Spatial distribution of groundwater resources sustainability in China, Science of the total environment, 672, 551-662, https://doi.org/10.1016/j.scitotenv.2019.03.457.

Lizjen, J. P. A., Otte, P., Van-Dreumel, M. 2014. Towards sustainable management of groundwater: Policy developments in The Netherlands, Science of the total environment, 485-486, 804-809, https://doi.org/10.1016/j.scitotenv.2014.02.081.

Madani, K., Mariño, M. A. 2009. System dynamics analysis for managing Iran's Zayandeh-Rud river basin. Water resources management, 23(11), 2163-2187, https://doi.org/10.1007/s11269-008-9376-Z.

Maliva, R., \& Missimer, T. 2012. Arid lands water evaluation and management, Springer Science \& Business Media, https://doi.org/10.1007/978-3-642-29104-3.

Michelsen, A. M., \& Young, R. A. 1993. Optioning agricultural water rights for urban water supplies during drought, American Journal of Agricultural Economics, 75(4), 1010-1020, https://doi.org/10.2307/1243988.

Niazi, A., Prasher, S., Adamowski, J., Gleeson, T. 2014. A system dynamics model to conserve arid region water resources through aquifer storage and recovery in conjunction with a dam, Water, 6(8), 2300-2321, https://doi.org/10.3390/w6082300.

Phan, T. D.; Smart, J. C. R.; Shahin, O.; Capon, S. J. 2018. Assessment of the vulnerability of a coastal freshwater system to climatic and non-climatic changes: A system dynamics approach, Journal of Cleaner Production, 183, 940-955, https://doi.org/10.1016/j.jclepro.2018.02.169.

Rygaard, M., Binning, P.J., Albrechtsen, H.J. 2011. Increasing urban water self-sufficiency: New era, new challenges, Journal of Environmental Management, 92(1), 185-194, https://doi.org/10.1016/j.jenvman.2010.09.009.

Statistical Centre of Iran. 2016. Investigation on the process of changes in the structure and composition of Iran's population and its future until the horizon year 2051, Statistical Centre of Iran, https://www.amar.org.ir/Portals/0/Files/fulltext/1398/N_brtsvtjkvaato1430.pdf.

Sušnik, J., Vamvakeridou-Lyroudia, L.S., Savić, D.A. and Kapelan, Z., 2012. Integrated System Dynamics Modelling for water scarcity assessment: Case study of the Kairouan region. Science of the total environment, 440, pp.290-

508 Tianhong, L.; Songnan, Y.; Mingxin, T. 2019. Simulation and optimization of water supply and demand balance in 509 Shenzhen: A system dynamics approach. Journal of Cleaner Production, 207, 882-893, 510 https://doi.org/10.1016/j.jclepro.2018.10.052. 
511 UN Water. 2015. Water and sustainable development from vision to action, means and tools for implementation and

512 the role of different actors. In Report of the 2015 UN-water Zaragoza conference, Zaragoza, Spain,

513 https://www.un.org/waterforlifedecade/pdf/WaterandSD Vision to_Action-2.pdf.

514 Vo, H.V., Chae, B., Olson, D.L. 2002. Dynamic MCDM: The case of urban infrastructure decision making, International

515 Journal of Information Technology \& decision making, 1(2), 269-292,

516 https://doi.org/10.1142/S0219622002000166.

517 Xi, X., Poh, K. L. 2013. Using system dynamics for sustainable water resources management in Singapore, Procedia

518 Computer Science, 16, 157-166, https://doi.org/10.1016/j.procs.2013.01.017.

519 Yang, Z., Song, J., Cheng, D., Xia, J., Li, Q., \& Ahamad, M. I. (2019). Comprehensive evaluation and scenario

520 simulation for the water resources carrying capacity in Xi'an city, China. Journal of environmental management,

$521230,221-233$, https://doi.org/10.1016/j.jenvman.2018.09.085.

522 Yousefi, H., Zahedi, S., Niksohkahn, M.H., 2018. Modifying the analysis made by water quality index using multi

523 criteria decision making methods, Journal of African Earth Sciences, 138, 309-318,

524 https://doi.org/10.1016/j.jafrearsci.2017.11.019.

525 Yousefi, H., Zahedi, S., Niksohkahn, M.H., Momeni, M. 2019. Ten year prediction of groundwater level in Karaj plain

526 (Iran) using MODFLOW2005-NWT in MATLAB, Environmental Earth Sciences, In Press,

527 https://doi.org/10.1007/s12665-019-8340-y.

528 Zahedi, S., 2017. Modification of expected conflicts between Drinking Water Quality Index and Irrigation Water

529 Quality Index in water quality ranking of shared extraction wells using Multi Criteria Decision Making techniques,

530 Ecological Indicators, 83, 368-379, https://doi.org/10.1016/j.ecolind.2017.08.017.

531 Ziolkowska, J. R., Ziolkowski, B. 2016. Effectiveness of Water Management in Europe in the 21st Century, Water 532 Resources Management, 30 (7), 2261-2274, https://doi.org/10.1007/s11269-016-1287-9. 
Figures

(a)

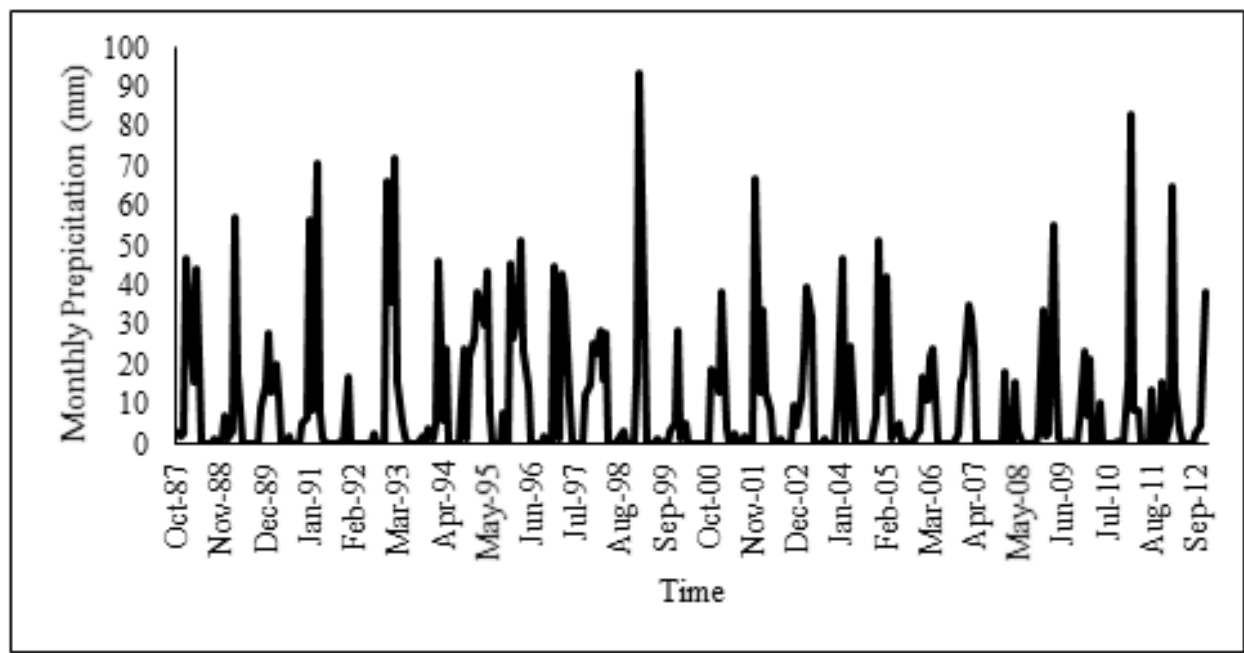

(b)

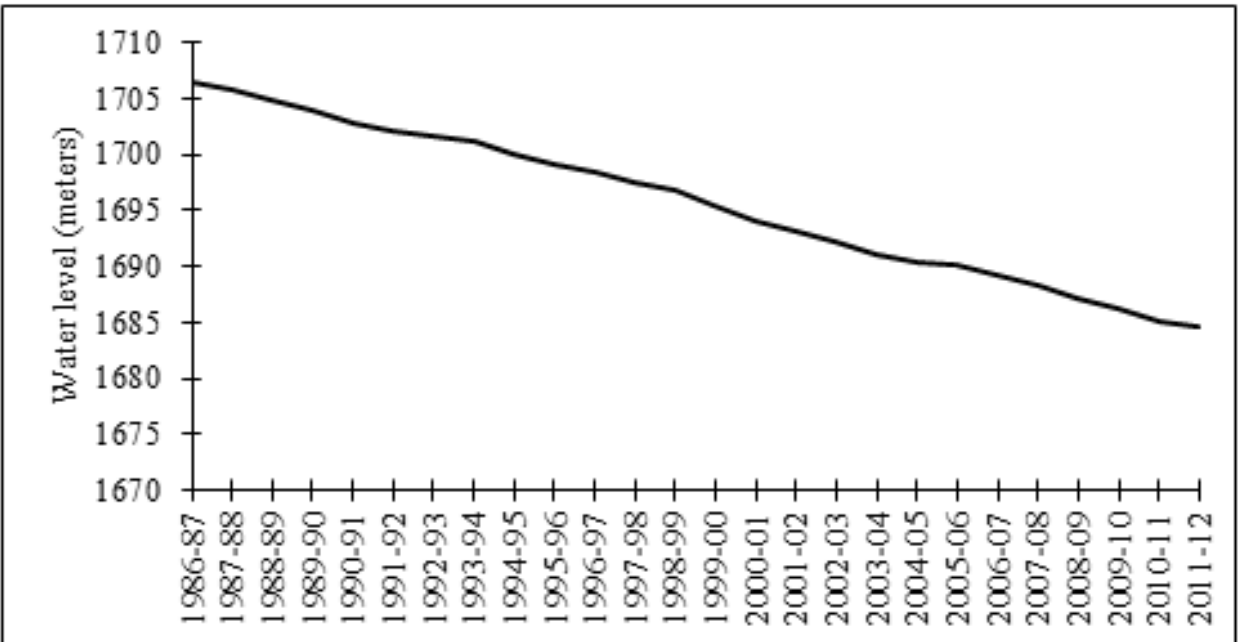

(c)

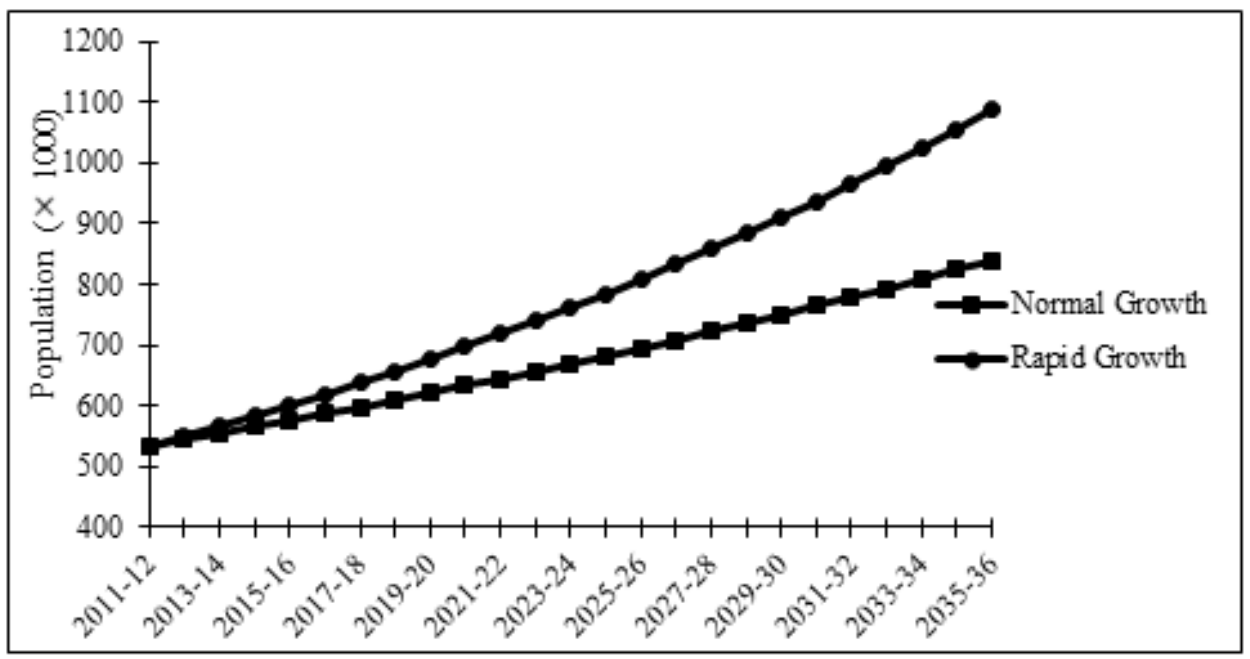

Figure 1

a) Monthly precipitation, b) annual variation of groundwater level and c) population growth in the case study 
(a)

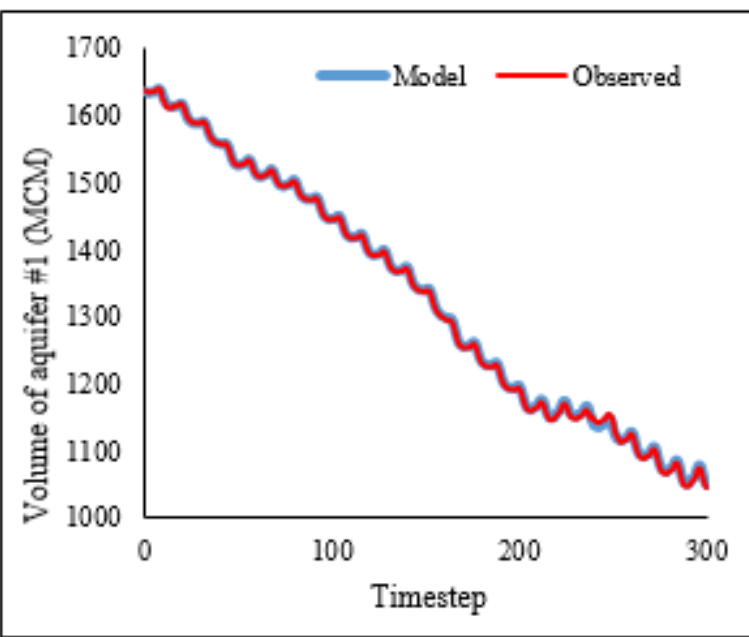

(c)

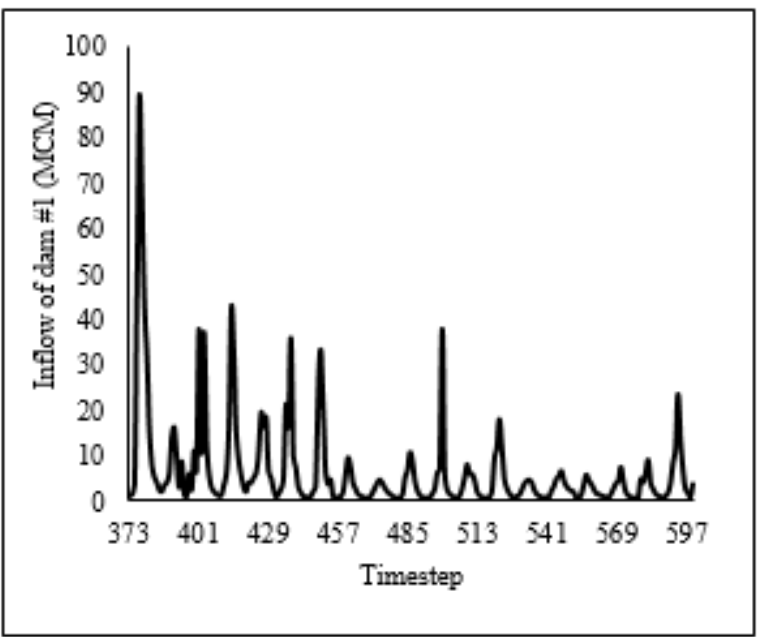

(b)

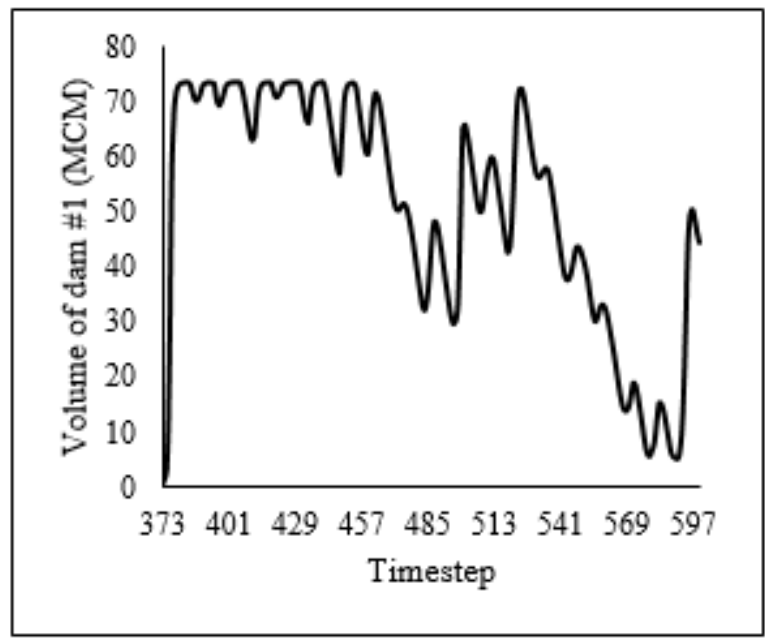

(d)

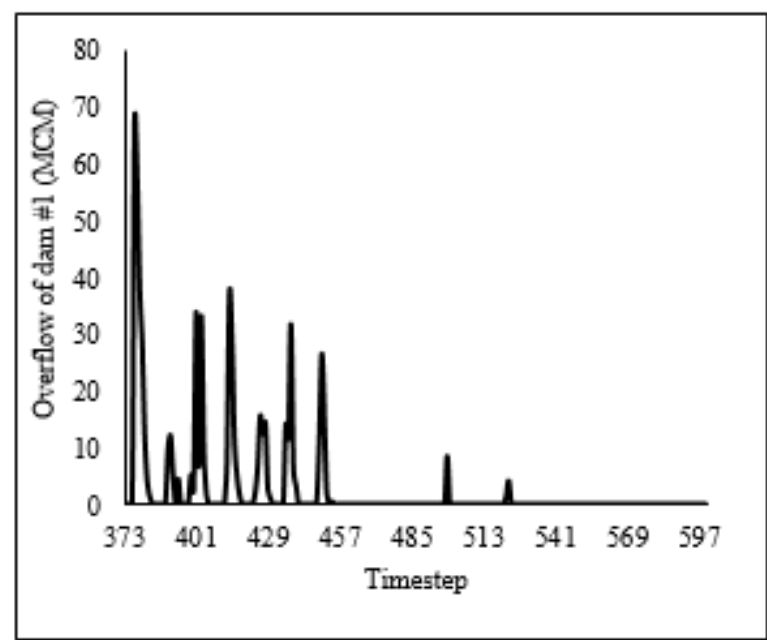

Figure 2

a) Water volume in aquifer \#1 for observed data and model output; variables of dam \#1 for b) reservoir volume, c) inflow, d) overflow. 


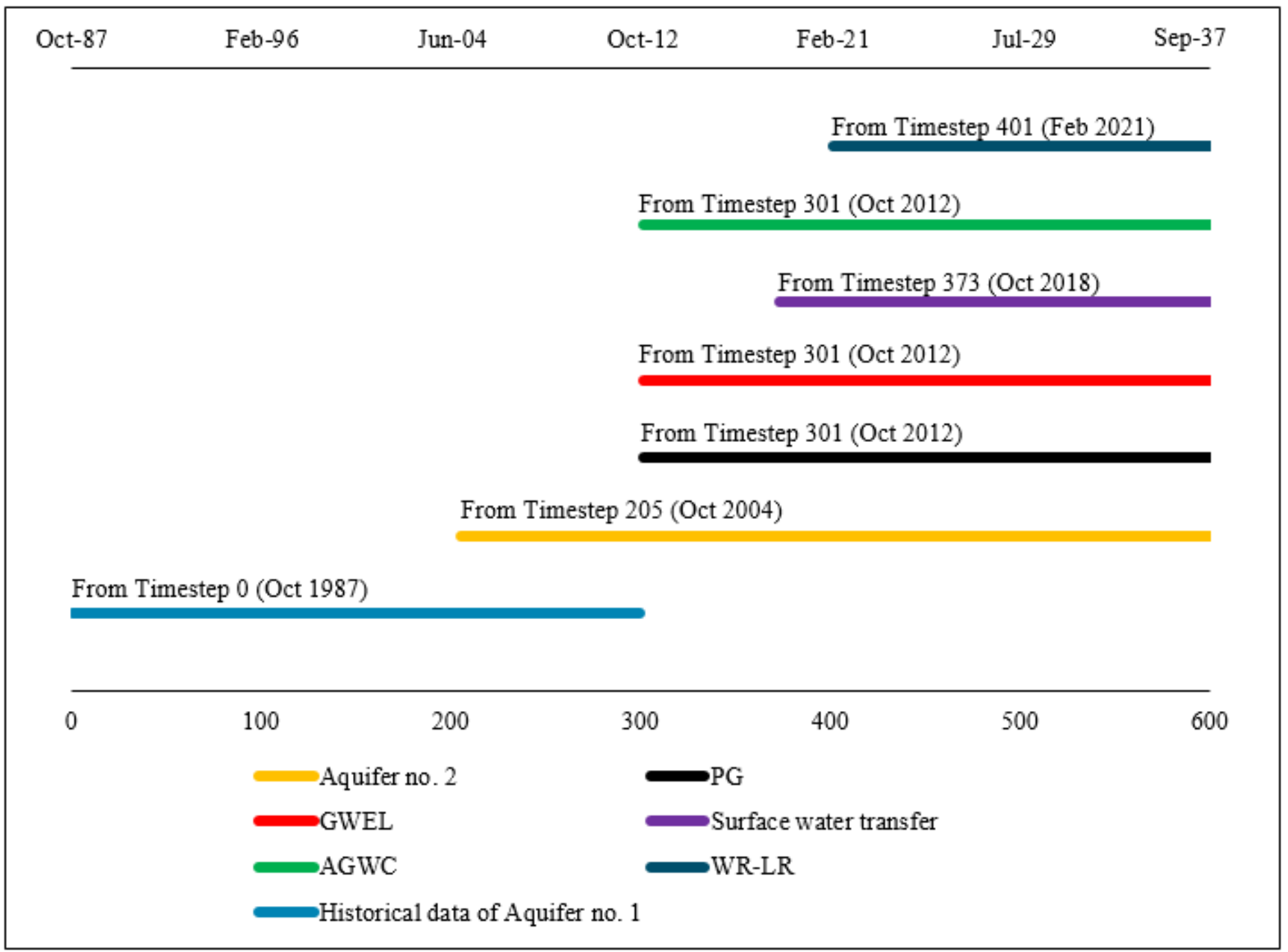

\section{Figure 3}

Timeframe of scenarios, strategies and water resources over the planning horizon 
(a)

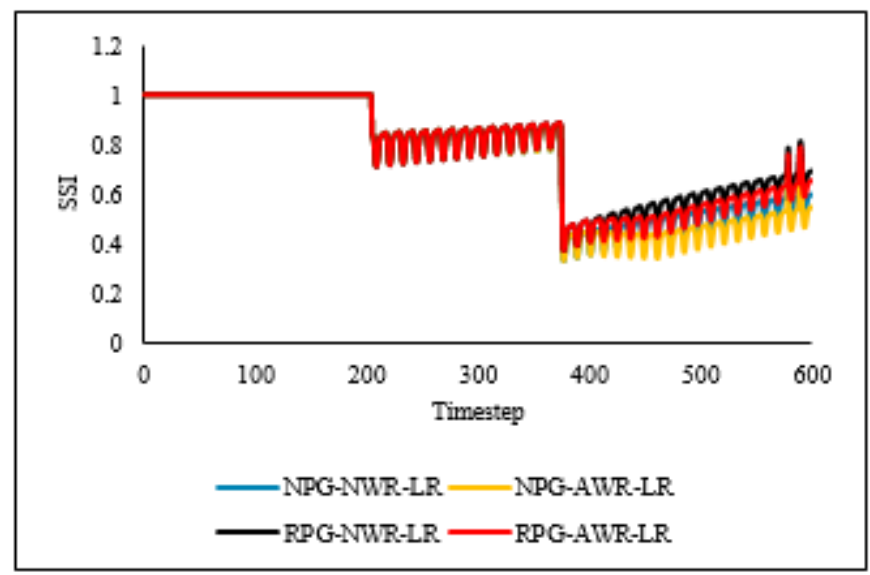

(b)

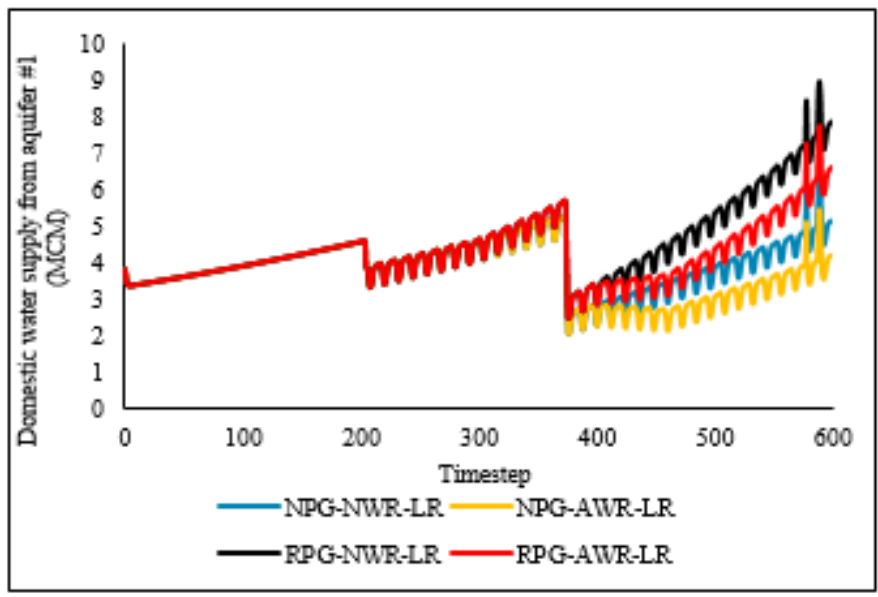

Figure 4

a) Self Sufficiency Index, b) Groundwater extraction from aquifer \#1 for domestic consumption. 


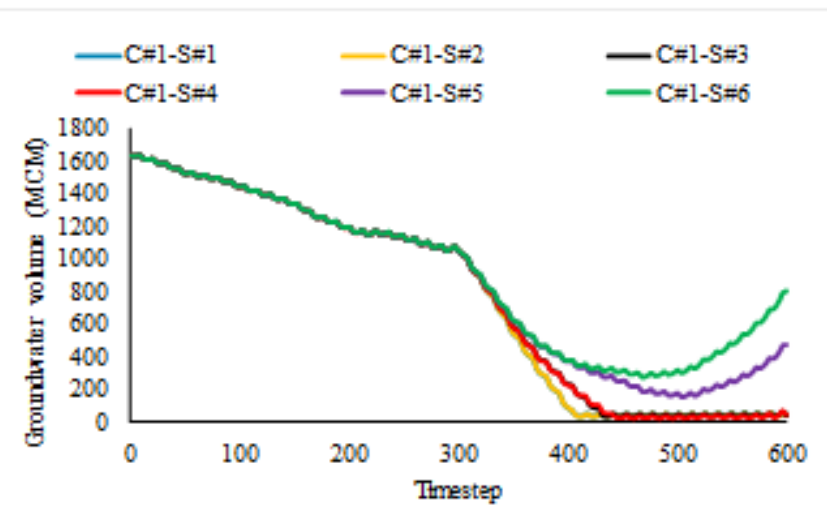

(a)

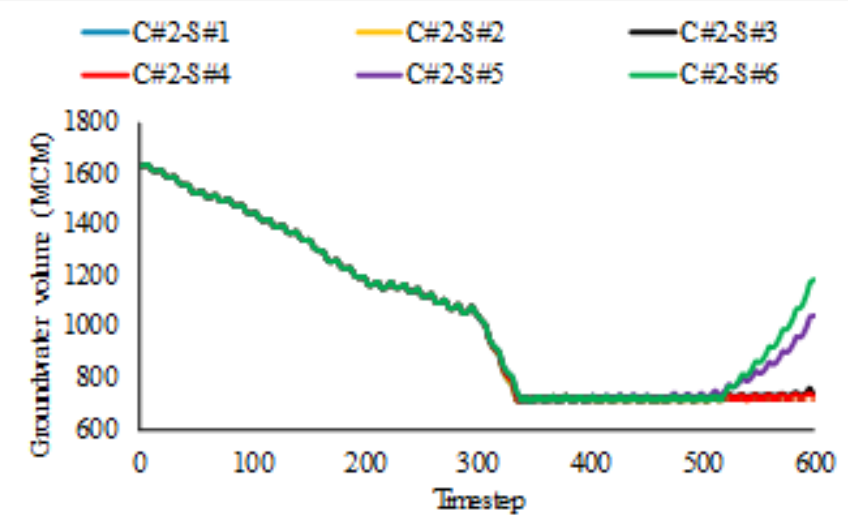

(c)
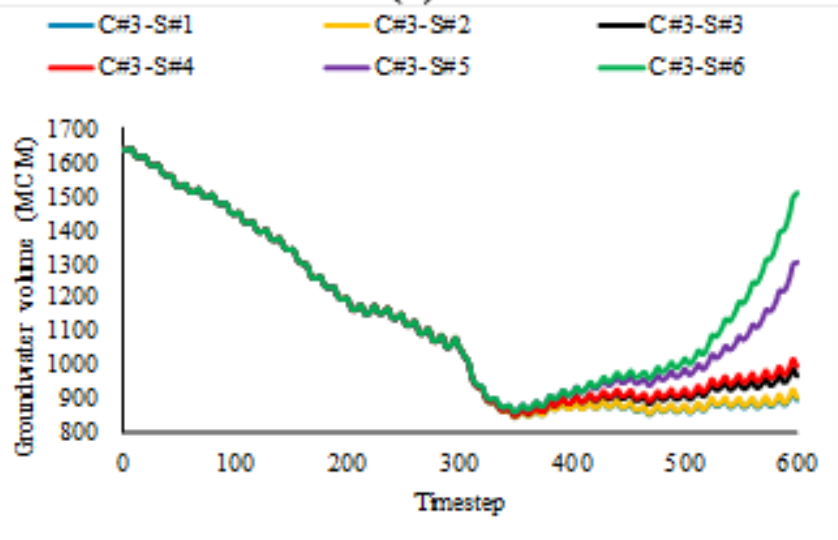

(e)

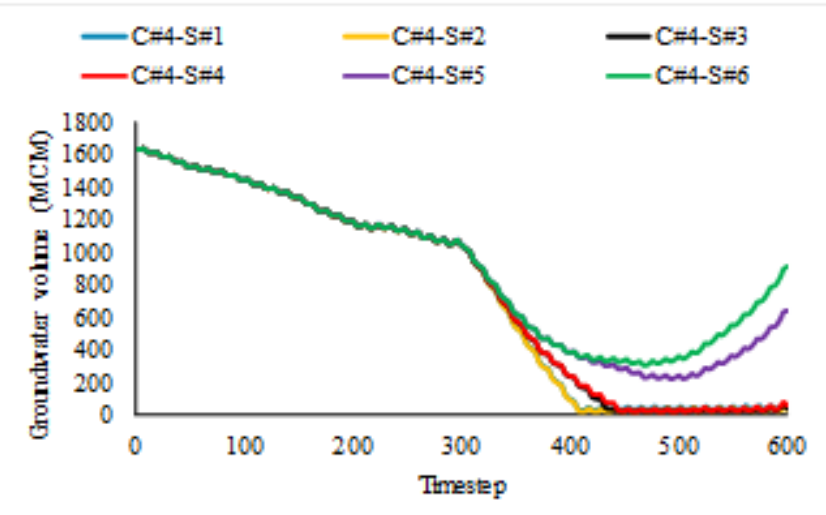

(b)

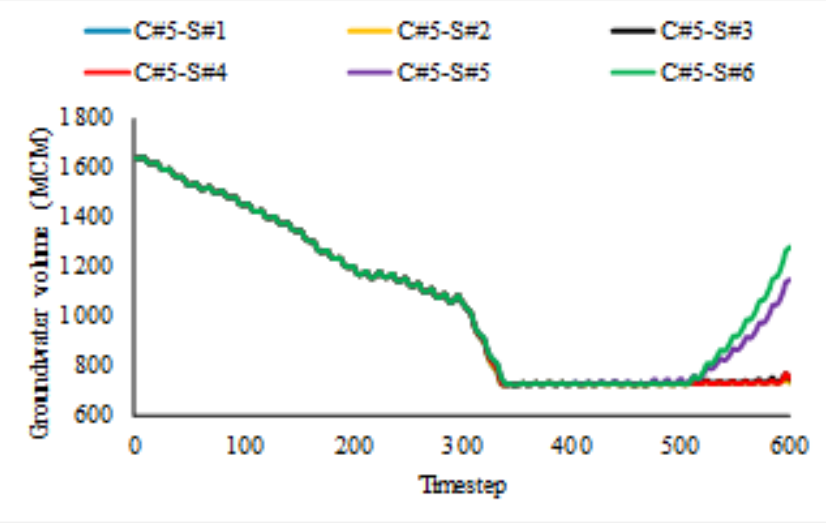

(d)

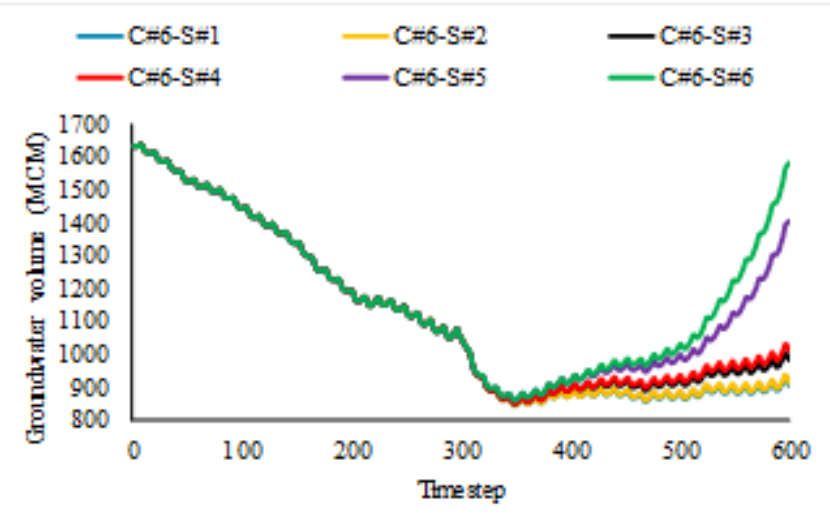

(f)

\section{Figure 5}

Variation of volume in aquifer \#1 for all strategies and scenario a) $C \# 1, b) C \# 4$, c) $C \# 2$, d) $C \# 5, e$ ) C\#3and f) C\#6 
(a)

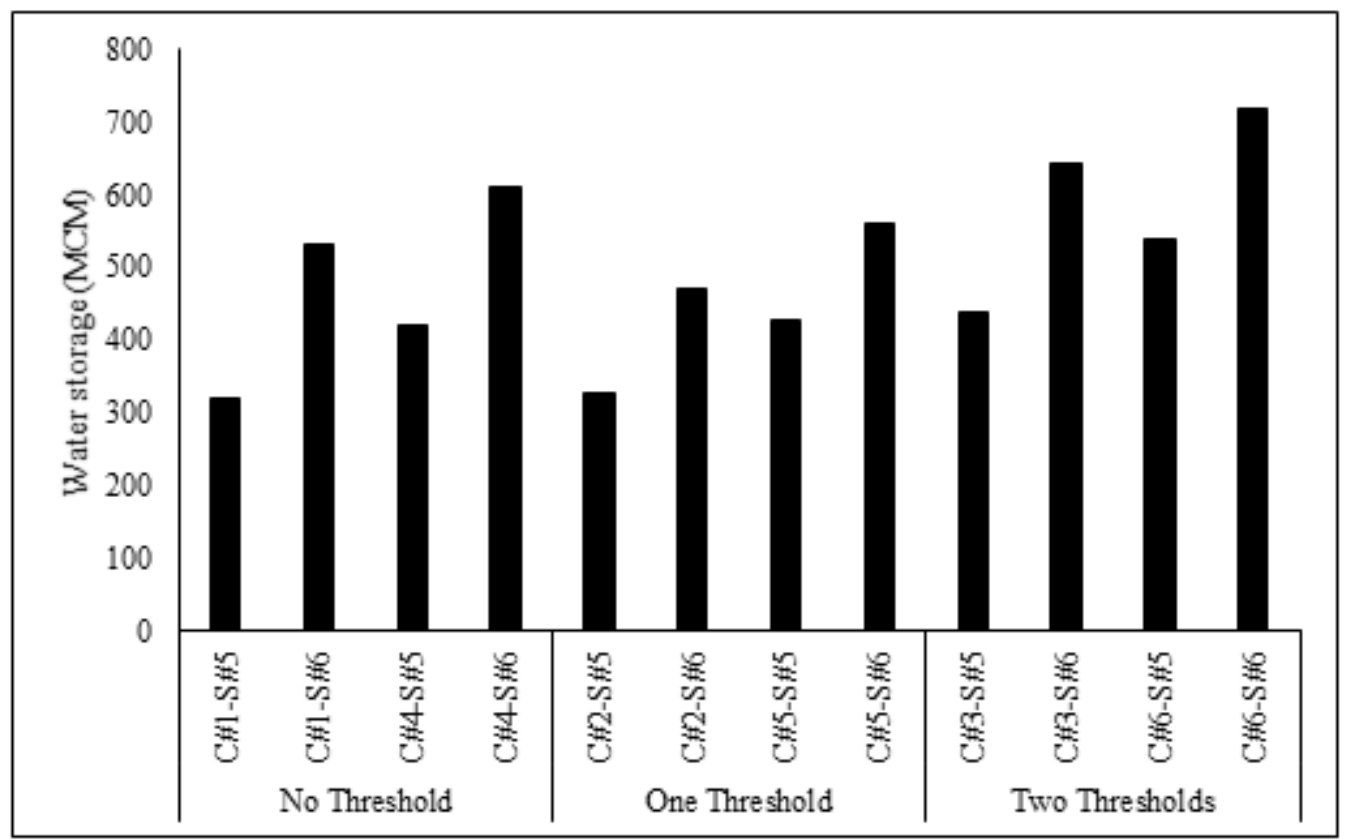

(b)

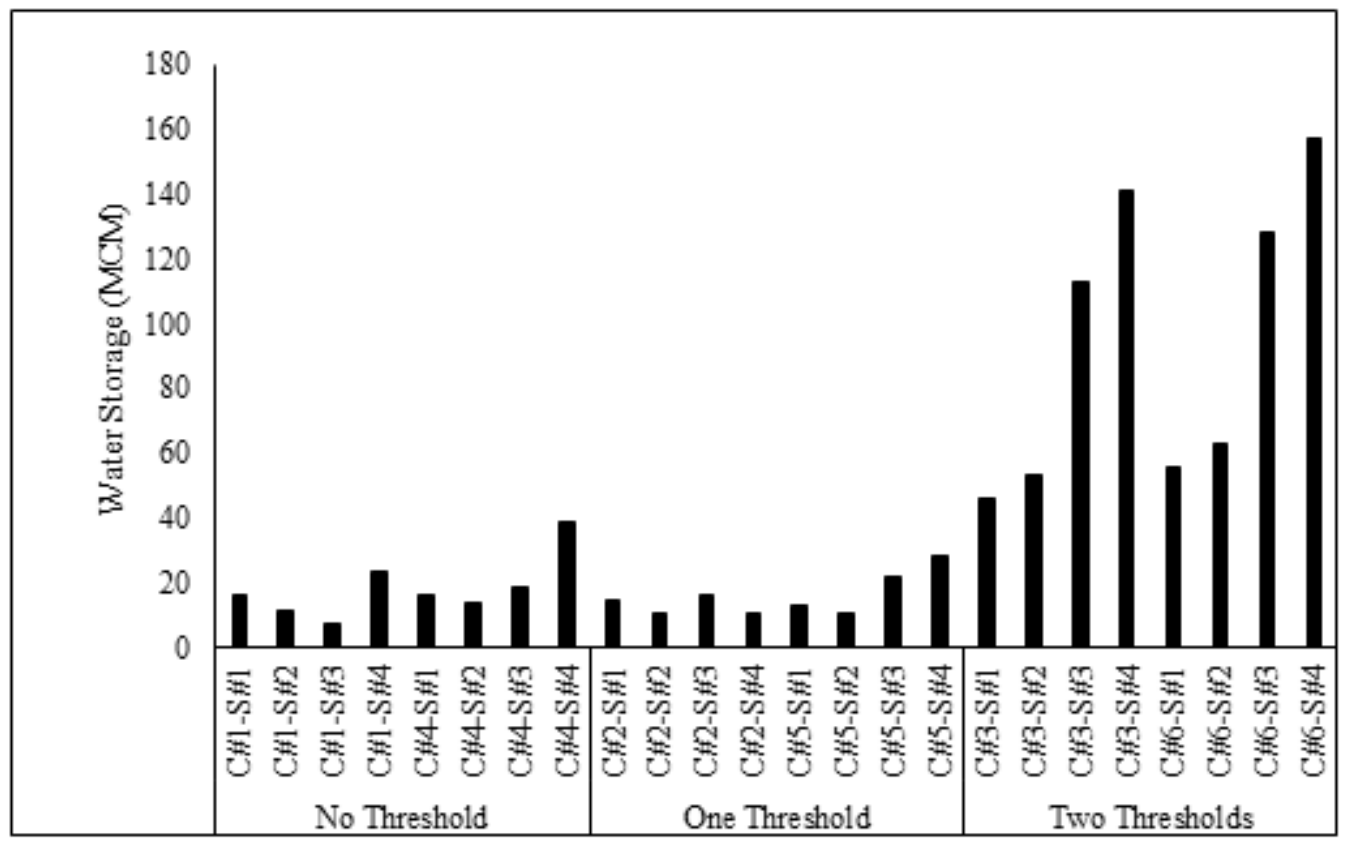

Figure 6

The volume difference of aquifer \#1 between the timestep with minimum volume and timestep 600 for strategies with a) water demand decrease S\#5 S\#6 and b) water demand constant S\#3 S\#4 and water demand increase S\#1 S\#2

\section{Supplementary Files}

This is a list of supplementary files associated with this preprint. Click to download.

- Supplamentary29032021.docx 